\title{
Investigation on the properties of ambient cured alkali activated binder concrete
}

\author{
M Talha Junaid ${ }^{1 *}$, Abdul Saboor Karzad ${ }^{1 \#}$, Moussa Leblouba ${ }^{1}$ \\ ${ }^{1}$ Department of Civil \& Environmental Engineering, College of Engineering, \\ University of Sharjah, Sharjah, P. O. Box 27272, UAE \\ * Present Address: Department of Civil Engineering, College of Engineering, American \\ University of Sharjah, Sharjah, P. O. Box 26666, UAE
}

\begin{abstract}
This research paper reports results of strength development properties of ambientcured alkali activated binders (AABs) and their reliance on different parameters, such as type of pre-cursor materials \& their proportions, type \& ratio of activators, and curing age. In this research study sodium silicate (SS) and sodium hydroxide (SH) solutions were used to activate a blend of low-calcium (class F) fly ash (FA) and ground granulated blast furnace slag (GGBFS). A total of 25 AABs mixes with various mix proportions are investigated in this research study. The results indicate that AABs can be manufactured with strength properties similar to ordinary Portland cement concrete (OPC). For further insight into the mechanical property variations of these samples SEM and EDS tests are conducted and their micrographs are presented here. A previously proposed analytical model to predict the compressive stress-strain response of these AABs is also modified in this study to better capture their post peak behaviour.
\end{abstract}

Keywords: Alkali activated binder, Elastic modulus, Compressive strength, Flexural strength, Stress-strain, SEM, EDS.

\section{OPEN ACCESS}

Received: December 28, 2020

Revised: April 25, 2021

Accepted: July 21, 2021

Corresponding Author:

M Talha Junaid

mjunaid@sharjah.ac.ae

Copyright: The Author(s). This is an open access article distributed under the terms of the Creative Commons Attribution License (CC BY 4.0), which permits unrestricted distribution provided the original author and source are cited.

\section{Publisher:}

Chaoyang University of

Technology

ISSN: 1727-2394 (Print)

ISSN: 1727-7841 (Online)

\section{INTRODUCTION}

Concrete is a commonly used construction material for structure and infrastructure development and the most widely used material second only to water. Therefore, the yearly global production of cement being the main binder of concrete, will only increase due to high demand of infrastructure growth (Davidovits, 1994; US Geological-Survey, 2013; Shehab et al., 2016). The production of cement not only adds $7 \%$ of the total manmade greenhouse gas emission $\left(\mathrm{CO}_{2}\right)$ to the atmosphere but also produces some other environmentally hazardous material such as $\mathrm{SO}_{3}$ and $\mathrm{NO}_{x}$ (Malhotra, 2002; McCaffrey, 2002; Fernández-jiménez, 2006; Lloyd and Rangan, 2010; Shehab et al., 2016). $\mathrm{CO}_{2}$ emissions resulting from OPC production can be divided into two halves: one coming from calcination of limestone while the other one is due to the fossil fuel combustion for the kiln (Hardjito et al., 2008).

To tackle the increase of these environmentally harmful products due to production of Portland cement (PC), alternative pozzolanic materials like metakaolin, fly ash, silica fume, GGBFS, and rice husk ash have been used as cement replacement (Ganesh and Muthukannan, 2018). These pozzolanic materials have made some impact on the carbon footprint of cement, however, this has been rather limited. More recently, researchers have focused on development of binders that do not uses Portland cement in full (Hassan et al., 2019; Ahmed et al., 2021; Shrivas et al., 2021). Alkali activated binders (AABs) are one such group of binders that have come to the forefront as a possible replacement for OPC. AABs are formed by activating silica $\left(\mathrm{SiO}_{2}\right)$ and alumina $\left(\mathrm{Al}_{2} \mathrm{O}_{3}\right)$ rich industrial by-products using a strong metallic alkaline solution. (Davidovits and Orlinski, 1988; Davidovits, 1991; Lloyd and Rangan, 2010; Topark-Ngarm et al., 2015). 
AABs do not depend on calcination of limestone as is the case in Portland cement production. The calcination of limestone is one of the major contributors to the production of $\mathrm{CO}_{2}$ in Portland cement production which is known as man-made greenhouse gas emission (McCaffrey, 2002). Therefore, AABs are expected to reduce man-made greenhouse gas emissions by $80 \%$ (Kong et al., 2006; Fernández-jiménez, 2006; Lloyd and Rangan, 2010).

In the past two decades $\mathrm{AABs}$ as an alternative to OPC concrete, has been under focus and investigated with the view to industrialize this material. Adding to the advantage in reduction of $\mathrm{CO}_{2}$ emissions, $\mathrm{AABs}$ can acquire similar or even superior mechanical properties to OPC concrete (Hassan et al., 2019; Chandrakanth and Koniki, 2020). Moreover, AABs exhibit high early strength, high durability and can maintain strength in severe conditions such as corrosive environment, elevated temperature, and high radiation (Binici, 2013). Despite the aforementioned advantages, there are many challenges facing AABs that need to be tackled in order to be used as a mainstream sustainable construction material. One of the main challenges is the reliance of the mechanical properties of AABs on the source of precursor materials and the activation system. The other challenge is varied setting time and low workability of high calcium fly ash AABs (Chindaprasirt et al., 2012; Topark-Ngarm et al., 2015). Finally, AABs require high temperature curing regime to attain substantial mechanical properties.

Several studies conducted on development and properties of AABs concluded that physical and mechanical properties of AABs is dependent on many variables: ratio of alkaline activator solution, SH concentration (Molarity), alkaline activator to fly ash ratio, amount of GGBFS as partial replacement to fly ash, and curing conditions (Fernándezjiménez, 2006; Diaz et al., 2010; Diaz-Loya, et al., 2011; Lee and Lee, 2013; Junaid et al., 2014a; Junaid et al., 2015, 2016; Junaid et al., 2017; Nath and Sarker, 2017). Many researchers reported on the general enhancement of AABs properties when fly ash is partially replaced by GGBFS (Ravikumar et al., 2010; Deb et al., 2014; Nath and Sarker, 2014).

Nath and Sarker (2014) added small quantities of GGBFS to low-calcium fly ash-based AABs that were cured at ambient conditions. They added GGBFS up to $30 \%$ of total binder and achieved a compressive strength of $55 \mathrm{MPa}$ at 28 days. They also reported that concretes having silicate to hydroxide ratio equal to 2.5 showed decreased slump and setting time than the mixtures with 1.5 and 2.0 ratios. Nath and Sarker (2015) in another research, studied the relationship between the experimental and predicted values of modulus for AABs using a proposed analytical model. They reported that the modulus of ambient cured AABs is $25-30 \%$ lower than that of OPC.
Another study by Deb et al. (2014) found good correlation between the development of the tensile strength and the compressive strength of ambient cured fly-ash AABs that were blended with slag. It was concluded that the methods of predicting the tensile strength of OPC concrete from their compressive strength recommended in AS 3600 and ACI 318 codes worked well with the ambient cured AABs. Hardjito et al. (2008) studied the setting time and strength properties of low calcium fly ash AABs and concluded that the compressive strength increases as the concentration of alkaline activator increases. A study conducted by Jaarsveld et al. (Van Jaarsveld et al., 2002) investigated the effect of curing process on properties of $\mathrm{AABs}$, found that curing at elevated temperature resulted in cracking and can impose adverse effect on properties of GPC.

Despite these investigations on properties and behaviour of AABs, there is a need for extensive investigation particularly regarding mechanical properties (i.e., compressive strength, modulus of elasticity, flexural strength, etc.) of ambient cured AABs. On the other hand, for AABs to become a dependable building material a reliable stress-strain relationship needs to be established. The focus of this experimental program is to study the mechanical properties of ambient cured AABs. To this end, 25 different types of mixes were prepared and around 400 samples were tested. The chemical composition and morphology of these ambient cured AABs were also studied. Finally, a stress-strain model is presented that accurately predicts the compressive response of such concretes.

\section{EXPERIMENTAL PROGRAMME}

\subsection{Materials}

Locally attained GGBFS and low calcium fly ash (Class F) imported from India was used as pre-cursor material in this study. Table 1 shows chemical composition of the fly ash and GGBFS used in this experimental program as found using X-Ray Fluorescence (XRF). The precursor material was activated using a combination of Sodium silicate (SS) and sodium hydroxide (SH) solutions. SS solution with density of 1.296 to $1.396 \mathrm{~g} / \mathrm{ml}$ (produced by German based company Merck $\mathrm{KGaA}$ and procured from Emirates Scientific \& Technical Supplies (ESTS), UAE) was used. The SS solution had $27 \% \mathrm{SiO}$ and $8 \% \mathrm{Na}_{2} \mathrm{O}$. SH solution (12M) was made by dissolving $98 \%$ purity flakes in water. Only one molarity of SH solution was used in this study. Coarse aggregates with a nominal size of $10 \mathrm{~mm}$, absorption of $0.7 \%$, and specific gravity of 2.68 , were used, while fine aggregates were a blend of $5 \mathrm{~mm}$ crushed aggregates and dune sand, in the ratio of $60-40$ percentage. The specific gravity of these combined fine aggregates was 2.62 and an absorption of $1 \%$. 
Junaid et al., International Journal of Applied Science and Engineering, 18(5), 2020339

Table 1. Chemical composition of fly ash and GGBFS using x-ray fluorescence (XRF)

\begin{tabular}{ccccccccccccccc}
\hline Material & $\mathrm{Al}_{2} \mathrm{O}_{3}$ & $\mathrm{SiO}_{2}$ & $\mathrm{CaO}$ & $\mathrm{SO}_{3}$ & $\mathrm{Na}_{2} \mathrm{O}$ & $\mathrm{MgO}$ & $\mathrm{K}_{2} \mathrm{O}$ & $\mathrm{TiO}_{2}$ & $\mathrm{MnO}_{2}$ & $\mathrm{Fe}_{2} \mathrm{O}_{3}$ & $\mathrm{NiO}$ & $\mathrm{ZnO}$ & $\mathrm{SrO}$ \\
\hline GGBFS & 5.7 & 32.4 & 50.6 & 2.4 & - & 6.5 & - & 0.5 & 0.7 & 0.6 & - & - & - \\
FA & 10.9 & 59.8 & 8.7 & 1.5 & 1.0 & 7.5 & 1.4 & 1.1 & 0.2 & 7.5 & 0.03 & 0.04 & 0.08 \\
\hline
\end{tabular}

\subsection{Specimens Preparation}

The mixing procedure for making AABs is similar to that of the OPC concrete. Alkaline solutions were prepared at least 24 hours before mixing. The mixing was done at room temperature. Fine and coarse aggregates in saturated surface dry (SSD) condition were mixed with fly ash and GGBFS for 2 minutes with some portion of water. Silicate's solution, if present in the mix, was then added and mixed for 3 minutes. Hydroxide was then added and mixed for another 2 minutes. The required amount of water was then added and mixed for another 2 minutes. The framework provided by Junaid et al. (2015) was used to proportion the mixes. The water to binder ratio was calculated using the following equation:

$w / b=\frac{W_{\text {free }}+W_{O H}+W_{S i}}{F A+G+S_{O H}+S_{S i}}$

Where;

$W_{\text {free }}=$ Weight of free water in the system

$W_{O H}=$ Weight of water content of the $\mathrm{OH}$ solution

$W_{S i}=$ Weight of water content of the silicate solution

$F A=$ Weight of Fly Ash

$G=$ Weight of GGBFS

$S_{O H}=$ Weight of solid content of the $\mathrm{OH}$ solution

$S_{S i}=$ Weight of solid content of the silicate solution

A total of five Sets, each consisting of five different mixes (resulting in a total of 25 different mixes) were cast in this study. The only variable within each Set was the ratio of GGBFS to fly ash (i.e., from zero $\%$ in $\operatorname{mix} 1$ to $100 \%$ in mix5-except Set 4 and 5) while all the other proportions were kept constant throughout the mixes in each Set. Between Sets, the Sodium Silicate to Sodium Hydroxide ratio was changed to study its effect on the mechanical properties. The Geopolymer solids to Alkali Liquid (GS/AL) ratio was kept constant for all sets in the study. However, depending on the workability requirements additional water was added to the mix. The differences between the sets are the ratio of SS to $\mathrm{SH}$ (denoted by letter $\mathrm{R}$ ) and the $\mathrm{w} / \mathrm{b}$ ratio. Table 2 summarizes the mix design proportions of the mixes used in this study.

Cylinders and prisms with nominal dimensions of 100x200 mm and 100x100x500 mm respectively were cast. The cylinders were filled layer by layer and compacted by manual strokes using a steel tamper. Additionally, after the samples were filled, they were further compacted using the vibration table. The exposed surfaces of the specimens were wrapped in watertight membrane after casting to minimize water loss during setting. After 24 hours the sample were removed from their moulds and kept in room temperature until time of testing.

\subsection{Test Scope}

Compressive strength, splitting tensile strength and modulus of elasticity tests were performed on cylindrical specimen according to the ASTM standard tests ASTM C39/C39M - 16b (2016), ASTM C496 (2006), and ASTM C469/C469M (2013), respectively. The flexural strength tests were performed on prismatic beams according to the ASTM C78/C78M (2002). The compression test was conducted using a $3000 \mathrm{kN}$ hydraulic compression machine (shown in Fig. 1(a)) with a pace rate of $2.4 \mathrm{kN} / \mathrm{s}$, while splitting or indirect tensile testing test was conducted at a slower pace rate of $0.94 \mathrm{kN} / \mathrm{s}$ using the same machine.

Furthermore, the stress-strain response of the samples was captured by testing the cylindrical samples at 28 days under compression in deformation control mode using rings as per the standard. LVDTs mounted on rings were placed on either side of the specimen to capture the deformation. In the current study, for each mix one cylinder was tested with the rate of $0.01 \mathrm{~mm} / \mathrm{sec}$ until the load level reached half the expected strength of the sample. Afterwards, as programmed the loading rate automatically changed to $0.005 \mathrm{~mm} / \mathrm{sec}$ until the failure of the sample.

Scanning electron microscopy (SEM) and Energy Dispersive X-ray Spectroscopy (EDS) testing was conducted on samples particles collected during destructive tests (Cylinders and prisms tests) in order to record the morphology and analyse the reaction products. SEM test was performed by taking images using Tescan VEGA 3 XMU while the EDS spectra test was performed using Oxford Instruments X-max 50 EDS and an SDD and LN free detector with a resolution of $127 \mathrm{eV}$. The samples were kept under desiccator for drying. A thin layer of Carbon was deposited using Quorum Technology carbon evaporator prior to the SEM analysis. All SEM tests were done at 28 days. 


\section{International Journal of Applied Science and Engineering}

Junaid et al., International Journal of Applied Science and Engineering, 18(5), 2020339

Table 2. Mix design of the AAB concrete studied in this research paper

\begin{tabular}{|c|c|c|c|c|c|c|c|c|c|c|c|c|}
\hline \multirow{3}{*}{\multicolumn{2}{|c|}{ Mix ID }} & \multirow{2}{*}{\multicolumn{2}{|c|}{$\begin{array}{c}\text { Pre-cursor } \\
\text { materials } \mathrm{kg} / \mathrm{m}^{3}\end{array}$}} & \multicolumn{3}{|c|}{ Activators } & \multirow{2}{*}{\multicolumn{3}{|c|}{$\begin{array}{c}\text { Aggregates } \\
\mathrm{kg} / \mathrm{m}^{3}\end{array}$}} & \multirow{4}{*}{$\begin{array}{l}\text { Water } \\
\mathrm{kg} / \mathrm{m}^{3}\end{array}$} & \multirow{4}{*}{$\begin{array}{l}\mathrm{w} / \mathrm{b} \\
\text { Ratio }\end{array}$} & \multirow{4}{*}{$\begin{array}{l}\text { Unit volume } \\
\qquad \mathrm{m}^{3}\end{array}$} \\
\hline & & & & \multirow{3}{*}{$\frac{\mathrm{kg}}{\mathrm{SH}}$} & \multirow{3}{*}{$\mathrm{SS}$} & Ratio & & & & & & \\
\hline & & \multirow{2}{*}{ FA } & \multirow{2}{*}{ GGBFS } & & & \multirow{2}{*}{$\mathrm{R}$} & \multicolumn{3}{|c|}{ e $\quad$ Fine } & & & \\
\hline & & & & & & & $10 \mathrm{~mm}$ & $5 \mathrm{~mm}$ & Dune Sand & & & \\
\hline \multirow{5}{*}{ Set1 } & S1M1 & 425.0 & 0.0 & 165.0 & 0.0 & 0.0 & 1065 & 390 & 260 & 50.0 & 0.32 & 1.0 \\
\hline & S1M2 & 340.0 & 85.0 & 165.0 & 0.0 & 0.0 & 1065 & 390 & 260 & 50.0 & 0.32 & 1.0 \\
\hline & S1M3 & 212.5 & 212.5 & 165.0 & 0.0 & 0.0 & 1065 & 390 & 260 & 50.0 & 0.32 & 1.0 \\
\hline & S1M4 & 85.0 & 340.0 & 165.0 & 0.0 & 0.0 & 1065 & 390 & 260 & 50.0 & 0.32 & 1.0 \\
\hline & S1M5 & 0.0 & 425.0 & 165.0 & 0.0 & 0.0 & 1065 & 390 & 260 & 50.0 & 0.32 & 1.0 \\
\hline \multirow{5}{*}{ Set2 } & S2M1 & 425.0 & 0.0 & 82.5 & 82.5 & 1.0 & 1065 & 390 & 260 & 58.5 & 0.32 & 1.0 \\
\hline & $\mathrm{S} 2 \mathrm{M} 2$ & 340.0 & 85.0 & 82.5 & 82.5 & 1.0 & 1065 & 390 & 260 & 58.5 & 0.32 & 1.0 \\
\hline & S2M3 & 212.5 & 212.5 & 82.5 & 82.5 & 1.0 & 1065 & 390 & 260 & 58.5 & 0.32 & 1.0 \\
\hline & S2M4 & 85.0 & 340.0 & 82.5 & 82.5 & 1.0 & 1065 & 390 & 260 & 58.5 & 0.32 & 1.0 \\
\hline & S2M5 & 0.0 & 425.0 & 82.5 & 82.5 & 1.0 & 1065 & 390 & 260 & 58.5 & 0.32 & 1.0 \\
\hline \multirow{5}{*}{ Set3 } & S3M1 & 425.0 & 0.0 & 55.0 & 110.0 & 2.0 & 1065 & 390 & 260 & 60.0 & 0.32 & 1.0 \\
\hline & S3M2 & 340.0 & 85.0 & 55.0 & 110.0 & 2.0 & 1065 & 390 & 260 & 60.0 & 0.32 & 1.0 \\
\hline & S3M3 & 212.5 & 212.5 & 55.0 & 110.0 & 2.0 & 1065 & 390 & 260 & 60.0 & 0.32 & 1.0 \\
\hline & S3M4 & 85.0 & 340.0 & 55.0 & 110.0 & 2.0 & 1065 & 390 & 260 & 60.0 & 0.32 & 1.0 \\
\hline & S3M5 & 0.0 & 425.0 & 55.0 & 110.0 & 2.0 & 1065 & 390 & 260 & 60.0 & 0.32 & 1.0 \\
\hline \multirow{5}{*}{ Set4 } & S4M1 & 425.0 & 0.0 & 47.0 & 118.0 & 2.5 & 1065 & 390 & 260 & 60.0 & 0.32 & 1.0 \\
\hline & S4M2 & 403.7 & 21.3 & 47.0 & 118.0 & 2.5 & 1065 & 390 & 260 & 60.0 & 0.32 & 1.0 \\
\hline & S4M3 & 382.5 & 42.5 & 47.0 & 118.0 & 2.5 & 1065 & 390 & 260 & 60.0 & 0.32 & 1.0 \\
\hline & S4M4 & 361.3 & 63.7 & 47.0 & 118.0 & 2.5 & 1065 & 390 & 260 & 60.0 & 0.32 & 1.0 \\
\hline & S4M5 & 340.0 & 85.0 & 47.0 & 118.0 & 2.5 & 1065 & 390 & 260 & 60.0 & 0.32 & 1.0 \\
\hline \multirow{5}{*}{ Set5 } & S5M1 & 425.0 & 0.0 & 55.0 & 110.0 & 2.0 & 1065 & 390 & 260 & 30.0 & 0.26 & 1.0 \\
\hline & S5M2 & 382.5 & 42.5 & 55.0 & 110.0 & 2.0 & 1065 & 390 & 260 & 30.0 & 0.26 & 1.0 \\
\hline & S5M3 & 340.0 & 85.0 & 55.0 & 110.0 & 2.0 & 1065 & 390 & 260 & 30.0 & 0.26 & 1.0 \\
\hline & S5M4 & 297.5 & 127.5 & 55.0 & 110.0 & 2.0 & 1065 & 390 & 260 & 30.0 & 0.26 & 1.0 \\
\hline & S5M5 & 255.0 & 170.0 & 55.0 & 110.0 & 2.0 & 1065 & 390 & 260 & 30.0 & 0.26 & 1.0 \\
\hline
\end{tabular}

\section{RESULT AND DISCUSSIONS}

\subsection{Strength Properties}

\subsubsection{Compressive and Splitting Tensile Strength}

The 7 and 28-days average compressive and splitting tensile strength of the cylinders are illustrated in Fig. 1. From each mix, three cylinders were tested at 7 and 28 days, and the average test value is reported here.

Fig. 1(b) shows the strength development of samples in Set 1 with varying percentages of GGBFS. It is worth nothing that this set only used hydroxide as the sole activator $(\mathrm{R}=0)$. The maximum compressive strength at 7 days reached for this Set was $16 \mathrm{MPa}$ for samples of S1M5 with $100 \%$ GGBFS. All other mixes also returned similar strength values with the only exception being Mix 1 that showed a very low compressive strength (approximately 3 $\mathrm{MPa}$ ). Although addition of GGBFS improved the compressive strength of this set, the increase was rather small suggesting that single activator results in weak binders unfit for structural applications.

In contrast to Set 1 , the compressive strength development showed a very different trend for mixes in Set $2(\mathrm{R}=1)$. This set showed a high dependency on the amount of GGBFS used in the mix. Mix 1 (S2M1) with only fly ash as precursor material had a negligible compressive strength at 7 days. However, by adding GGBFS a significant increase in the compressive strength was observed. Fig. 1(c) shows the highest compressive strength for this Set was around 42 MPa for mixes containing more than 50\% GGBFS. A strength increases from 9.3 MPa to 23.6 MPa was observed when the GGBFS amount was changed from 20 to 50 percent for this set. When the GGBFS amount was further increased from 50 to 80 percent, the strength values changed from 23.6 $\mathrm{MPa}$ to $41.5 \mathrm{MPa}$. The change in strength for these mixes (i.e. from 9.3 MPa to $23.6 \mathrm{MPa}$ and from 23.6 MPa to $41.5 \mathrm{MPa}$ ) that shows an increase of 2.5 times and 1.6 times, respectively; were found to be in the same proportion as the change in the amount of GGBFS (from $20 \%$ to $50 \%$ and from 50 to $80 \%$ ). Any further increase in the amount of GGBFS (100\%) to the mixes did not change the compressive strength of the specimen. Since for S2M1 and S2M2, the observed compressive strength is below $20 \mathrm{MPa}$ at 7 days, these mixes may not be appropriate for structural applications. However, as the percentage of GGBFS is increased beyond $20 \%$ the resulting binder showed good mechanical strength properties.

For Set $3(\mathrm{R}=2.0)$ the pattern of strength development with respect to the percentage of GGBFS added to the mix was almost similar to the Set 2 strength development pattern 


\section{International Journal of Applied Science and Engineering}

Junaid et al., International Journal of Applied Science and Engineering, 18(5), 2020339

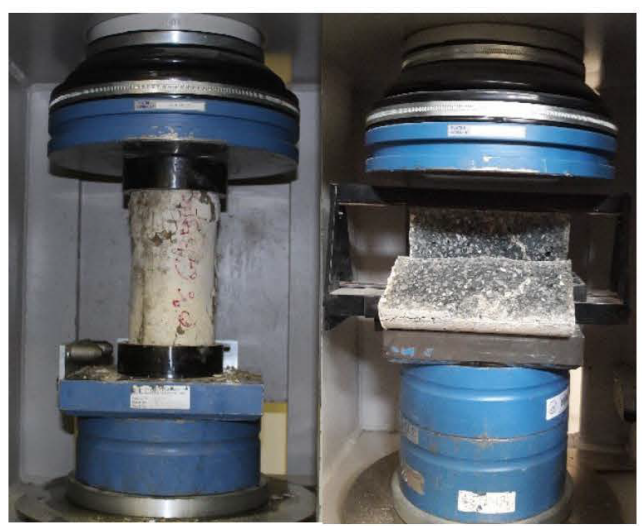

(a)

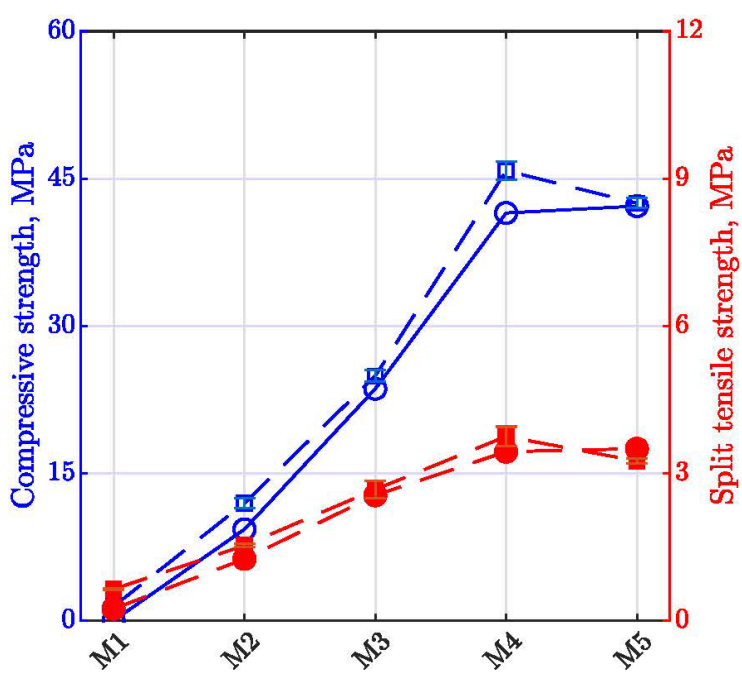

(c): Set2

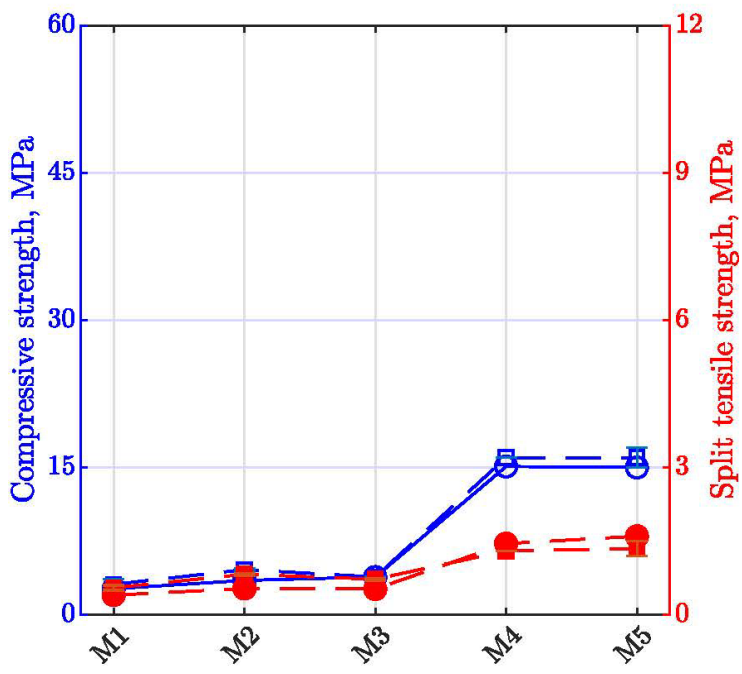

(e): Set4

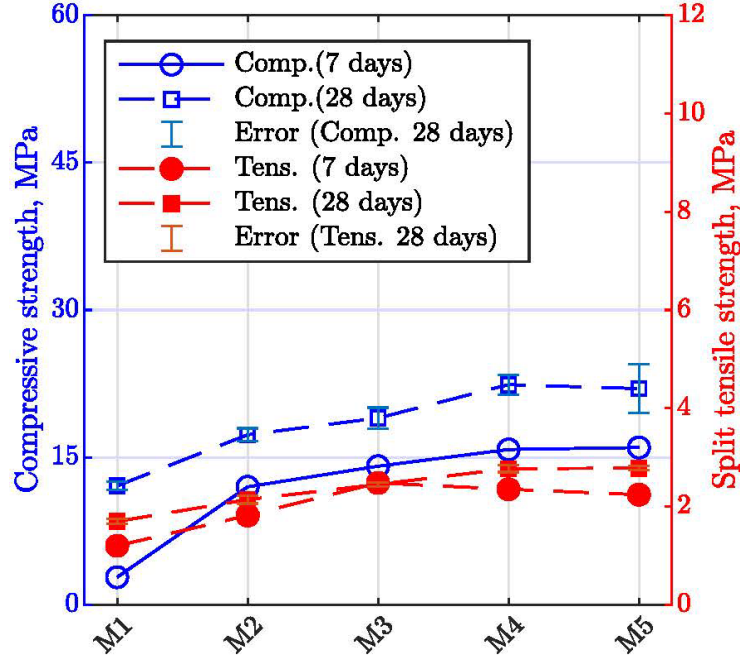

(b): Set1

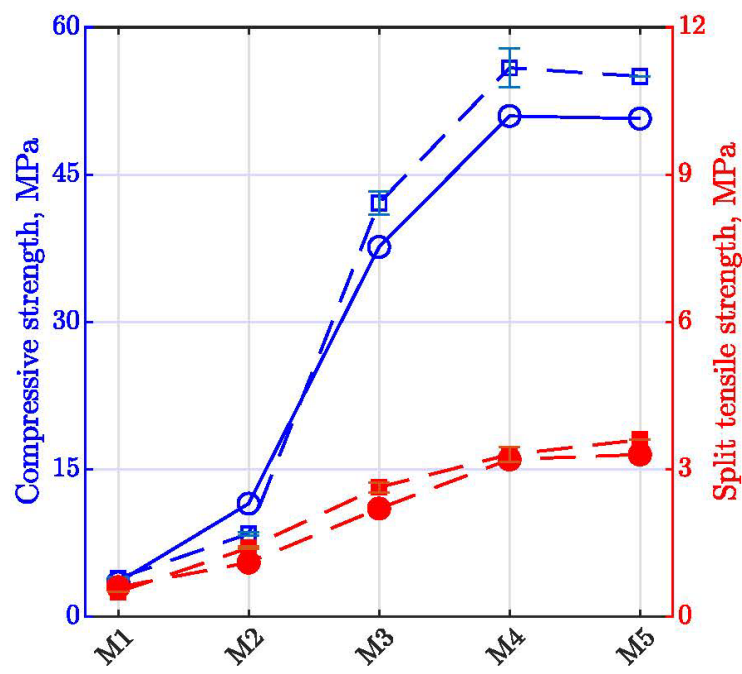

(d): Set3

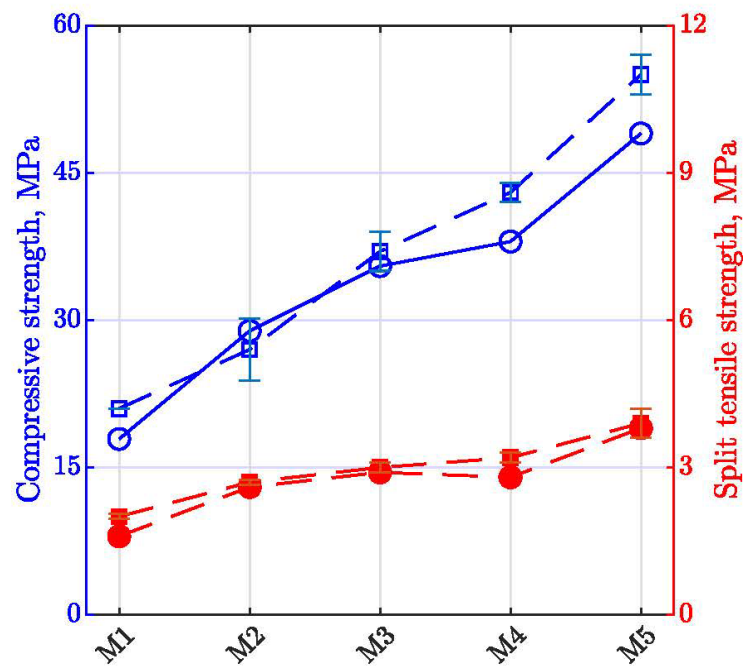

(f): Set5

Fig. 1. Compressive $\&$ split tensile strength $(7 \& 28$ days) of samples for all 5 sets 
as shown in Fig. 1(d). Mix 4 and 5 in Set 3 reached a compressive strength of around $50 \mathrm{MPa}$ at 7 days. As observed in Set 2, these mixes gained substantial strength when the GGBFS percentage was 50 and $80 \%$. Any further increase in the GGBFS amount did not have a positive effect on the strength development of the mixes. Similar to Set 2, mixes 1 and 2 are not suitable for strucutal application due to their low compressive strength.

Set 4 was designed to have low proportions of GGBFS, with the maximum of $20 \%$ replacement. These mixes also had a high silicate to hydroxide ratio $(\mathrm{R}=2.5)$. It was found that the strength development of these mixes was immune to the addition of GGBFS up to $10 \%$. As the GGBFS percentage was increased beyond $10 \%$ a slight jump in the strength development was observed. Increasing the GGBFS amount any further resulted in no change of compressive strength. However, the strength development of these mixes was not appropriate for use in structural engineering applications. As can be seen in Fig. 1(f), for Set 5 the gain in strength is proportional to the increase in GGBFS in the system. The maximum strength for this set was around $50 \mathrm{MPa}$ at 7 days. Also of note is the fact that for the mix S5M5 the maximum amount of GGBFS added was $40 \%$ of the total binder.

Further discussion on the strength development from a morphology point of view is made later in this paper (section 3.3 and 3.4).

As expected, the 28-day strength of all tested samples exhibited a similar trend to the 7-day strength as depicted in Fig. 1. Generally speaking, the compressive strength in all tested samples did not change significantly after the first 7 days period. This is also in agreement with earlier research (Li et al., 2017; Wattimena et al., 2017) which reported that unlike OPC the compressive strength of AABs develops in the first 7 days. After this initial period, there is not significant change in the strength of such concretes. However, current results obtained from Set 1 show a noticeable gain in strength after the initial 7 days period. This may indicate a dependency of strength development on the type of activator used. Other factors that may affect this behaviour are the precursor type and their proportions,

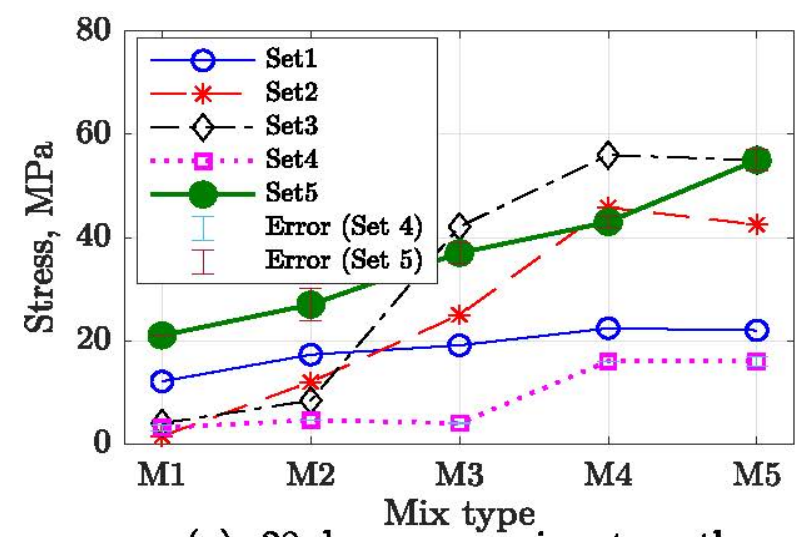

(a): 28-day compressive strength although more work is required to further investigate this effect and draw a definite conclusion. From the compressive strength results shown in Fig. 1 and Fig. 2 a, it can be concluded that the addition of higher amounts of GGBFS and sodium silicate resulted in higher overall compressive strength.

The evolution of the splitting strength of individual mixes is shown in Fig. 1 (b-f on the axis on the right) while Fig. 2(b) illustrates the development of splitting strength for all sets. It can be seen from Fig.s 1 (b-f) that there is no change in the splitting strength of AABs with time. It can therefore be concluded that AABs attain all their splitting tensile strength in the first 7 days after casting. This may be a desirable property to minimize the early cracking potential of AABs. Moreover, similar to OPC, the splitting tensile strength of $\mathrm{AABs}$ tested in this program return a value of almost $7-10 \%$ of their corresponding compressive strength. The maximum and minimum tensile strength reported were 3.9 $\mathrm{MPa}$ and 0.2 MPa for S5M5 and S2M1, respectively.

\subsubsection{Flexural Strength}

The flexural strength of specimens can be used as an indication of the tensile strength of concrete. Despite that, the flexural strength is, in general, higher than the indirect splitting tensile strength. Fig.3 (a) shows the flexural strength at 28 days of all 5 sets obtained by testing the standard beam samples $(500 \times 100 \times 100 \mathrm{~mm})$ in four points loading setup as shown in Fig. 3(b). In general, and as expected, the flexural strength test results show very similar pattern to the tensile and compressive strength of the mixes studied in this paper.

It is clear from Fig. 3 that the flexural strength increased with the increase in the percentage replacement of fly ash with GGBFS, in all sets except in Set 1 (which contains only $\mathrm{SH}$ as alkali activator), where after mix 3 the flexural strength started to deplete. The highest flexural strength was achieved by Set 2 and 3 with the AABs mix having 100\% GGBFS content.

It is also observed from Fig. 3 that increasing the alkali solution ratio (sodium silicate / sodium hydroxide) has a

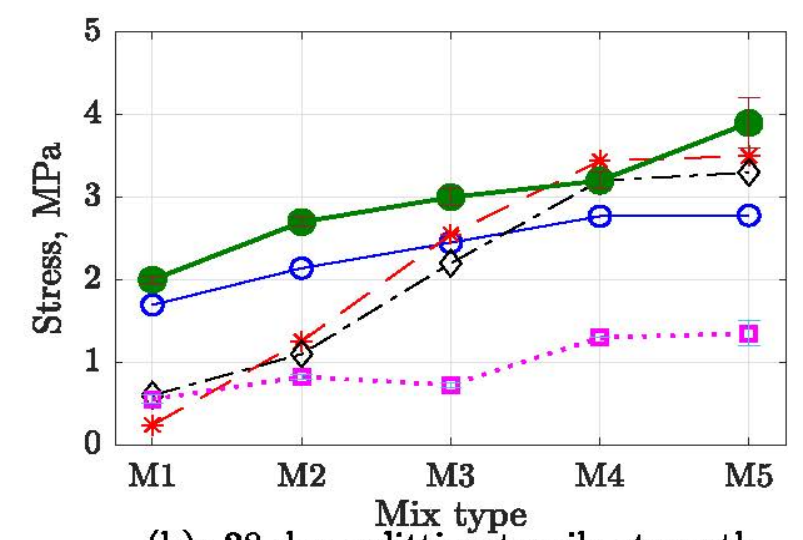

(b): 28-day splitting tensile strength

Fig. 2. Compressive and tensile strengths (28-days) of the samples for all 5 Sets combined 


\section{International Journal of Applied Science and Engineering}

Junaid et al., International Journal of Applied Science and Engineering, 18(5), 2020339

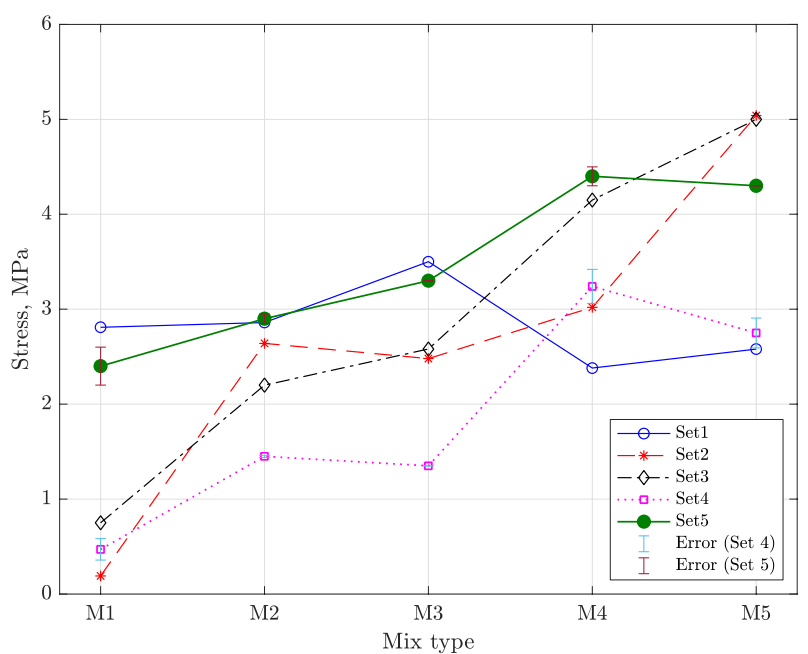

(a)

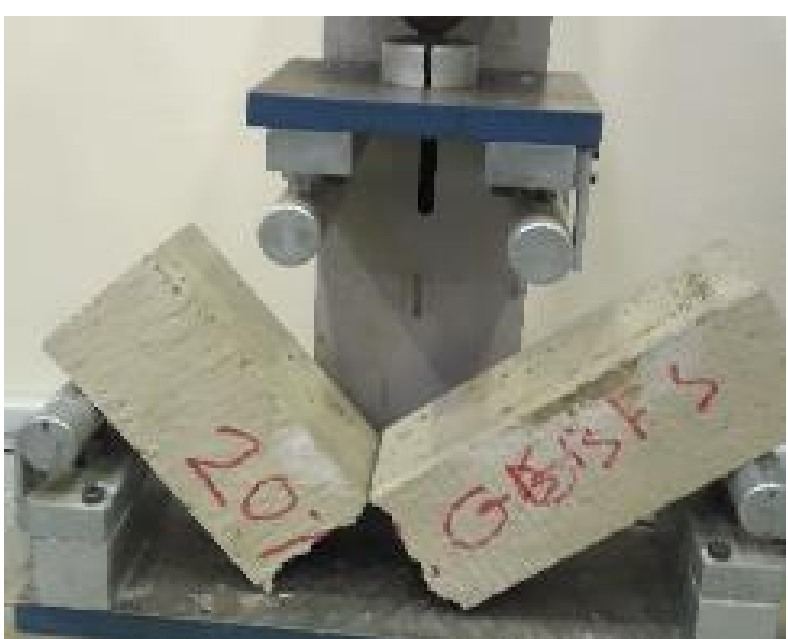

(b)

Fig. 3. (a) Flexural strength at 28 days for all 5 sets, (b) Flexural strength test setup

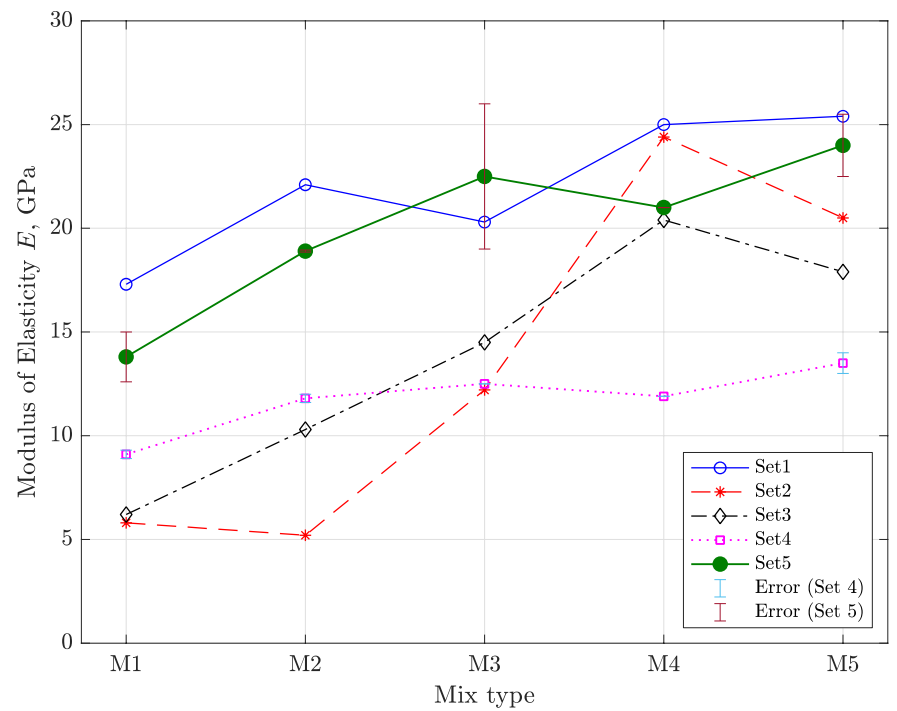

(a)

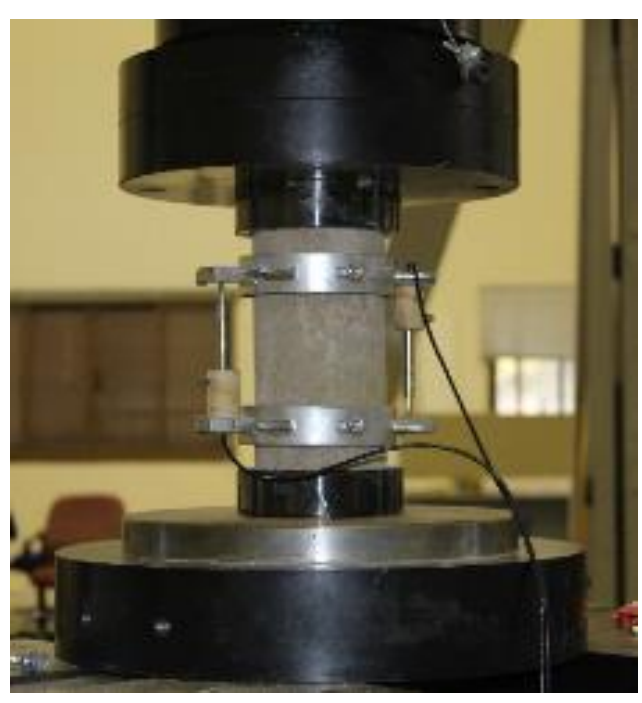

(b)

Fig. 4. (a) Results of young's modulus test at 28 days, (b) Young's modulus test setup

positive impact in improving the flexural strength. However, this is true up until a certain ratio $(\mathrm{R})$. In particular, when $\mathrm{R}$ increased from 2.0 (Set 5) to 2.5 (Set 4), the flexural strength values decreased significantly. According to Nath and Sarker (2015), flexural strength for mixtures having $40 \%$ alkali activator by volume of total mix showed increasing trend with the replacement of fly ash by GGBFS until 10\% and decreased after that. This implies that the amount and ratio of the activating system affect the flexural strength of $\mathrm{AAB}$ specimens until certain values. Further investigations of a combined effect of these two variables may be of concern for the researchers in the near future.

\subsubsection{Elastic Modulus and Density}

Compared to OPC, limited data is available on moduli values of AABs. However, it is widely accepted that the modulus of elasticity of AABs is generally lower than OPC samples of similar strengths (Nath and Sarker, 2017). This reduction in the moduli will dictate the flexural and axial stiffness of members made using AABs. It is therefore of importance that modulus of elasticity for ambient cured AABs be determined. Fig. 4 shows the experimental setup and the 28-day modulus of elasticity for specimens in this study.

The highest modulus values were consistently reported for Set 1 and were in good agreement with prediction models recommended by EuroCode 2 and ACI 318-14. Interestingly, the modulus values for Set 2 were significantly lower compared to Set1, although samples in Set 2 returned a higher compressive strength. The evolution of elastic modulus for Set 3 was very similar to the trend exhibited by its compressive strength, reaching a maximum value of $20 \mathrm{GPa}$. A similar trend was observed for Sets 4 and 


\section{International Journal of Applied Science and Engineering}

Junaid et al., International Journal of Applied Science and Engineering, 18(5), 2020339

Table 3. Summary of mechanical properties

\begin{tabular}{ccccccccc}
\hline $\begin{array}{c}\text { Mechanical } \\
\text { property }\end{array}$ & \multicolumn{2}{c}{$\begin{array}{c}\text { Compressive strength } \\
(\mathrm{MPa})\end{array}$} & \multicolumn{2}{c}{$\begin{array}{c}\text { Split tensile strength } \\
(\mathrm{MPa})\end{array}$} & $\begin{array}{c}\text { Flexural } \\
\text { strength (MPa) }\end{array}$ & $\begin{array}{c}\text { Elastic modulus } \\
(\mathrm{E})(\mathrm{GPa})\end{array}$ & $\begin{array}{c}\text { Density } \\
\left(\mathrm{kg} / \mathrm{m}^{3}\right)\end{array}$ \\
\cline { 2 - 10 } Mix ID & 7 Days & 28 Days & 7 Days & 28 Days & 28 Days & 28 Days & 7 Days & 28 Days \\
\hline S1M1 & 2.84 & 12.1 & 1.2 & 1.7 & 2.81 & 17.3 & 2318 & 2290 \\
S1M2 & 12 & 17.3 & 1.82 & 2.14 & 2.86 & 22.1 & 2389 & 2319 \\
S1M3 & 14.1 & 19.1 & 2.48 & 2.45 & 3.5 & 20.3 & 2317 & 2308 \\
S1M4 & 15.8 & 22.4 & 2.35 & 2.77 & 2.4 & 25 & 2344 \\
S1M5 & 16 & 22 & 2.24 & 2.78 & 2.6 & 25.4 & 2306 & 2299 \\
S2M1 & 0 & 1.45 & 0.64 & 0.24 & 0.2 & 5.8 & 2286 & 2230 \\
S2M2 & 9.3 & 11.96 & 1.53 & 1.26 & 2.6 & 5.2 & 2315 & 2318 \\
S2M3 & 23.6 & 24.9 & 2.67 & 2.55 & 2.5 & 12.2 & 2335 & 2356 \\
S2M4 & 41.5 & 45.8 & 3.75 & 3.44 & 3 & 24.4 & 2313 & 2359 \\
S2M5 & 42.2 & 42.5 & 3.25 & 3.5 & 5 & 20.5 & 2337 & 2375 \\
S3M1 & 3.5 & 4 & 0.5 & 0.6 & 0.75 & 6.2 & 2299 & 2230 \\
S3M2 & 11.5 & 8.5 & 1.4 & 1.1 & 2.2 & 10.3 & 2335 & 2307 \\
S3M3 & 37.6 & 42.1 & 2.6 & 2.2 & 2.6 & 14.5 & 2410 & 2398 \\
S3M4 & 51 & 55.9 & 2.8 & 3.2 & 4.15 & 20.4 & 2406 & 2339 \\
S3M5 & 50.7 & 55 & 3.6 & 3.3 & 5 & 17.9 & 2395 & 2342 \\
S4M1 & 2.65 & 3.1 & 0.4 & 0.55 & 0.47 & 9.1 & 2239 & 2259 \\
S4M2 & 3.5 & 4.6 & 0.535 & 0.825 & 1.45 & 11.8 & 2282 & 2268 \\
S4M3 & 3.85 & 3.85 & 0.525 & 0.725 & 1.35 & 12.5 & 2277 & 2244 \\
S4M4 & 15.1 & 16 & 1.45 & 1.3 & 3.24 & 11.9 & 2330 & 2244 \\
S4M5 & 15 & 16 & 1.6 & 1.35 & 2.75 & 13.5 & 2386 & 2308 \\
S5M1 & 18 & 21 & 1.6 & 2 & 1.22 & 13.8 & 2442 & 2413 \\
S5M2 & 29 & 27 & 2.6 & 2.7 & 2.12 & 18.9 & 2422 & 2397 \\
S5M3 & 35.5 & 37 & 2.9 & 3 & 2.34 & 22.5 & 2437 & 2448 \\
S5M4 & 38 & 43 & 2.8 & 3.2 & 3 & 21.0 & 2458 & 2410 \\
S5M5 & 49 & 55 & 3.8 & 3.9 & 3 & 24.0 & 2454 & 2426 \\
\hline
\end{tabular}

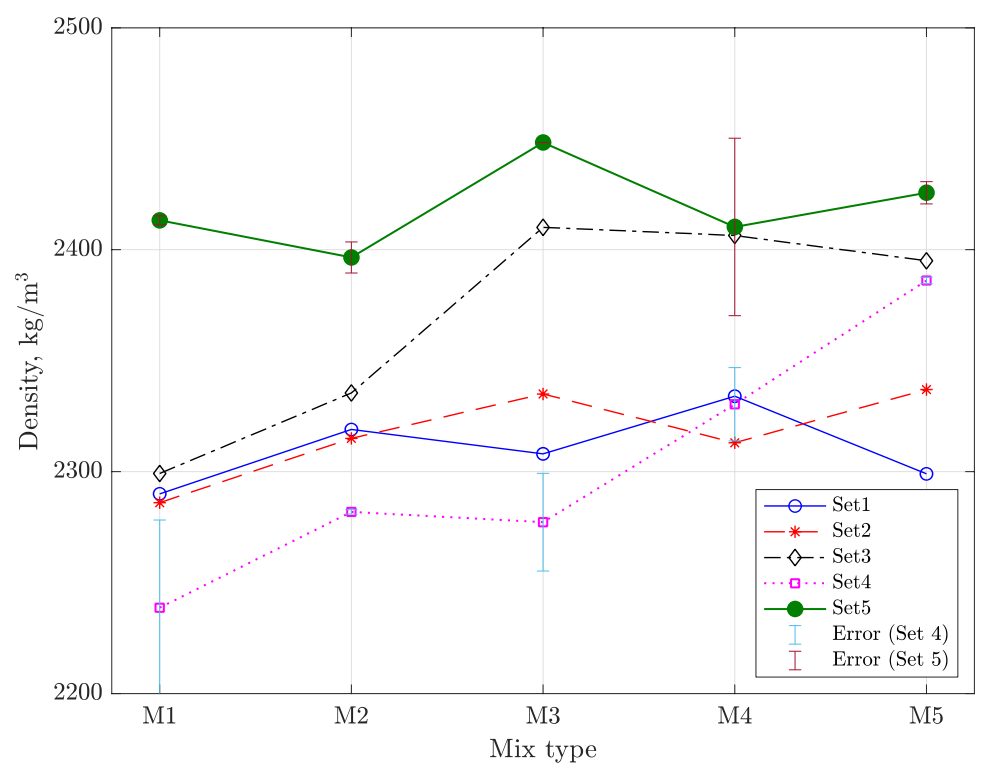

Fig. 5. Average density of all five sets

5 , with maximum values of $14 \mathrm{GPa}$ and $24 \mathrm{GPa}$ respectively. It may therefore be concluded that the addition of GGBFS increases the elastic modulus of ambient cured AABs, while the inclusion of sodium silicate reduces this property (Lee and Lee, 2013). It may also be concluded that the modulus values of ambient cured AABs is a function of its compressive strength, however, it does not necessarily follow the same prediction equations as established for OPC concretes. Tabulated summary of the results reported above is presented in Table 3. 
Fig. 5 shows the average density of all 5 sets which is calculated by dividing weight of cylindrical samples to its volume. The volume was determined using the average length and diameter of the samples. The average density of all samples was around $2350 \mathrm{~kg} / \mathrm{m}^{3}$, which is comparable to ordinary concrete (Mindess et al., 2003; Neville and Brooks, 2010).

\subsection{Stress - Strain Curves}

The behaviour and material properties of AABs may differ from OPC concrete due to the difference in their composition. Therefore, it is important for the purposes of design and simulation to understand the stress-strain behaviour of AABs. However, unlike the conventional OPC concrete that has a relatively well-known stress-strain behaviour, the stress-strain of geopolymer concrete is still not fully understood (Yadollahi and Benli, 2017) [36]. Therefore, the stress-strain behaviour of AABs prepared in this study was determined at 28 days and is presented in Fig. 6. As shown in the Fig.6 (a), Set 1 shows a strain of 0.002 at maximum stress, which continued to increase until full failure of the sample. This is also typical behaviour for OPC samples and design recommendations use this strain value for maximum stress.

However, the mixes in the remaining four sets that have both the activators ( $\mathrm{SH}$ and $\mathrm{SS}$ ) exhibited a strain value higher than the OPC concrete. Mix 4 and mix 5 of Set 2 (S2M4 and S2M5) exhibited a strain value of 0.003 at the maximum stress. However, the first three mixes of Set 2 that did not have structural application strength, strained higher than the strain limit of OPC concrete. Similarly, Set 3 showed strain values higher than OCP concrete for the mixes that have compressive strength in excess of $30 \mathrm{MPa}$, and even higher strain for the mixes which have lower compressive strength. On the other hand, Set 4 exhibited high strain values for only mixes 4 and 5 that have high compressive strengths, and very low strains as well as low compressive strength for the other three mixes in the set. Set5 mixes which all have high compressive strengths, exhibited strain values higher than OPC concrete at the peak load. It can be inferred from Fig. 6 that the peak point position is highly influenced not only by the strength of the sample but also by the amount of GGBFS added to the mix and the alkali activating system.

As presented in Fig. 6, all the samples in Set 1 (which were activated by SH solution only) provided good stress strain behaviour that is comparable to conventional OPC concrete. Whereas in Sets 2 and 3, mixes 4 and 5 (with higher percentages of GGBFS) showed more brittle failure compared to the rest of the mixes, with a sudden decline in stress in the post-peak softening stage.

The results of the stress-strain test conducted in this study were compared to the analytical model proposed by Junaid et al. (2017) as shown below. The model considered, which is derived from Collins et al. (1993), has the following form: $\sigma_{c}=f^{\prime} c \cdot \frac{\varepsilon_{c}}{\epsilon_{c m}} \cdot \frac{n}{n-1+\left({ }^{\varepsilon_{c}} / \epsilon_{c m}\right)^{n k}} \quad(M P a)$

Where $\varepsilon_{c}$ is strain at stress $\sigma_{c}, f^{\prime} c$ is the peak compressive strength, and $\varepsilon_{c m}$ is the strain at maximum strength. $\mathrm{n}$ and $\mathrm{k}$ factors are unitless and are found as following:

$n=0.7+\left(f_{c}^{\prime} / 23\right)$

$k=0.6+\left(f_{c}^{\prime} / 86\right)$ when $\varepsilon_{c} / \varepsilon_{c m}>1$,

and $k=1.0$ when $\varepsilon_{c} / \varepsilon_{c m} \leq 1$

For each value of $\varepsilon_{c}$, the values of $\sigma_{c}$ is computed using Equation (2), with factors $n$ and $k$ calculated using equations 3 and 4. However, this model does not account for the post peak behaviour of such concretes. A post peak reduction factor $(\lambda)$ was therefore proposed in the current study and used for the considered analytical model. To capture the post peak behaviour, $\lambda$ is multiplied to the $k$ value obtained from Equation (4), only after peak stress is reached. The post peak reduction factor may be calculated using the following equations:

$$
\begin{aligned}
& \text { For } f^{\prime} c \leq 25, \lambda=1.4 \times \frac{25}{\varepsilon_{c m}} \times 10^{-4} \leq 2 \\
& \text { For } f^{\prime} c>25, \lambda=1.1 \times \frac{f^{\prime} c}{\varepsilon_{c m}} \times 10^{-4} \leq 2
\end{aligned}
$$

Fig. 7 presents the results of the experimental stress-strain data along with the predictions by Junaid et al. (2017) model including the post peak reduction factor as proposed in this study. It can be noticed in Fig. 7 that the stress-strain behaviour of all the selected specimens is in good agreement with the models' predictions. Therefore, it can be concluded that Junaid et al. (2017) analytical model can be used to predict the stress-strain behaviour of AAB specimens. 


\section{International Journal of Applied Science and Engineering}

Junaid et al., International Journal of Applied Science and Engineering, 18(5), 2020339

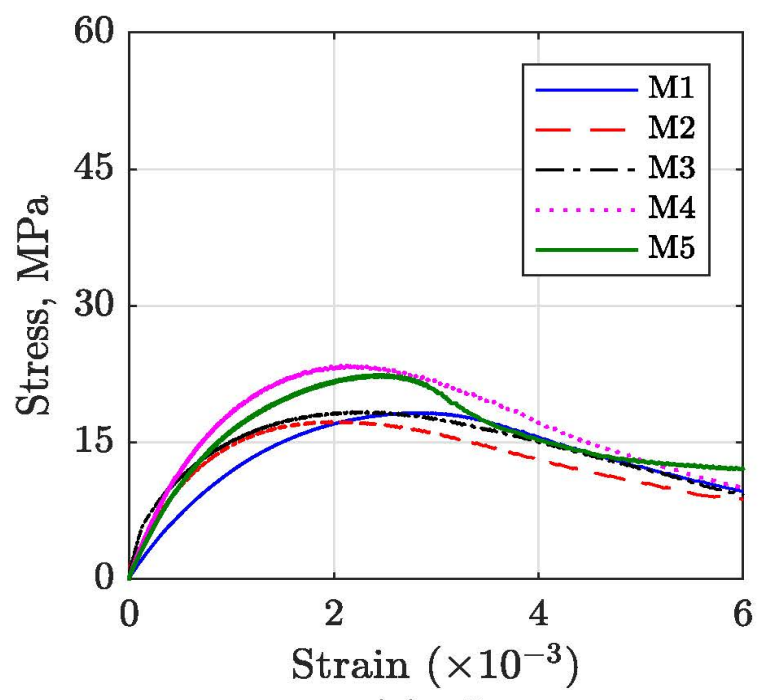

(a): S1

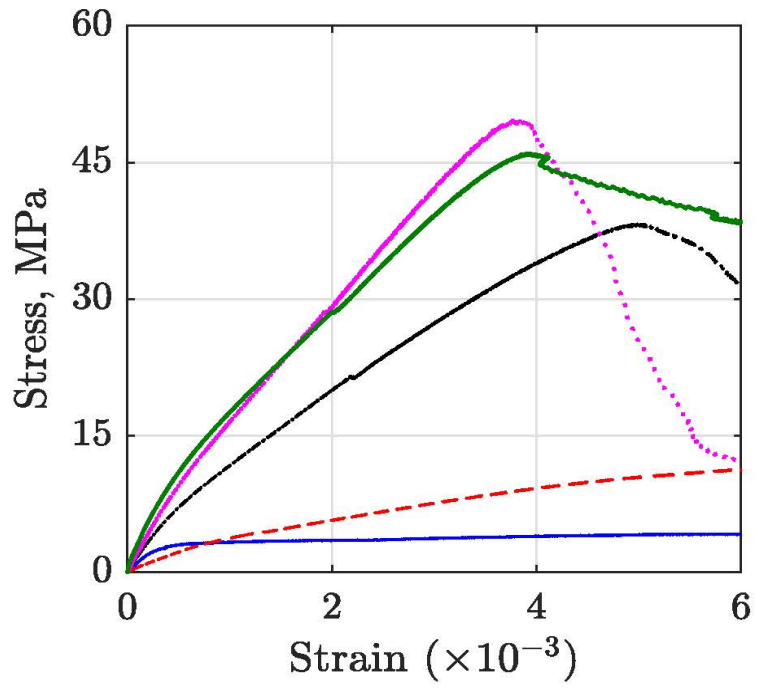

(c): S3

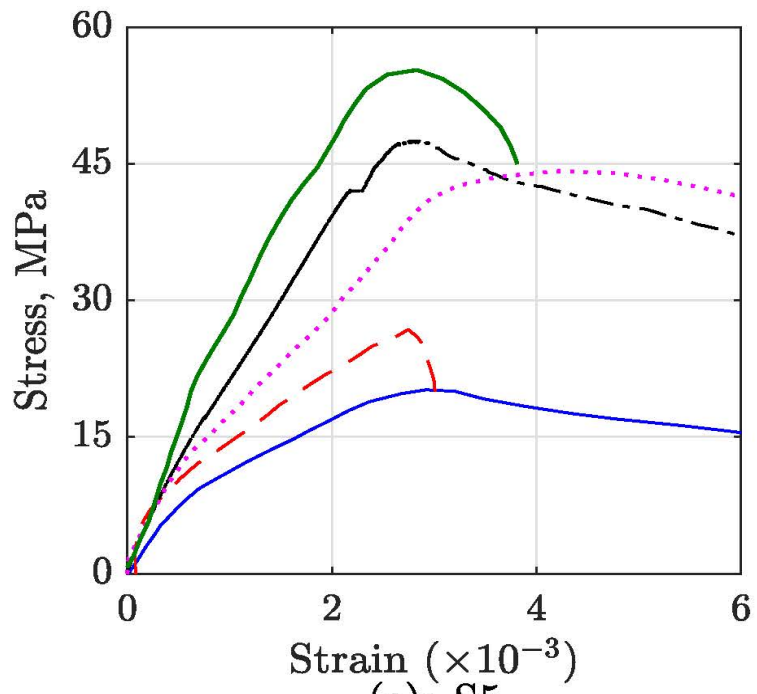

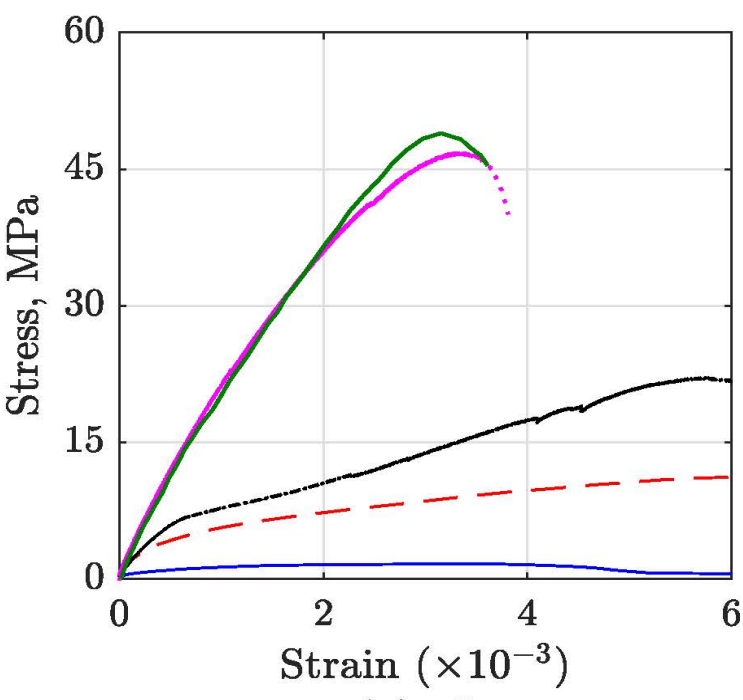

(b): S2

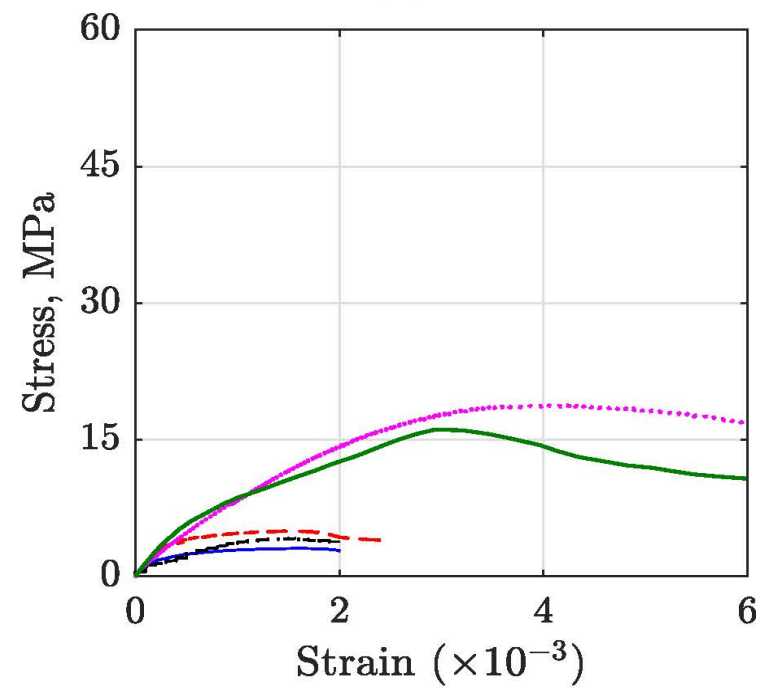

(d): 54

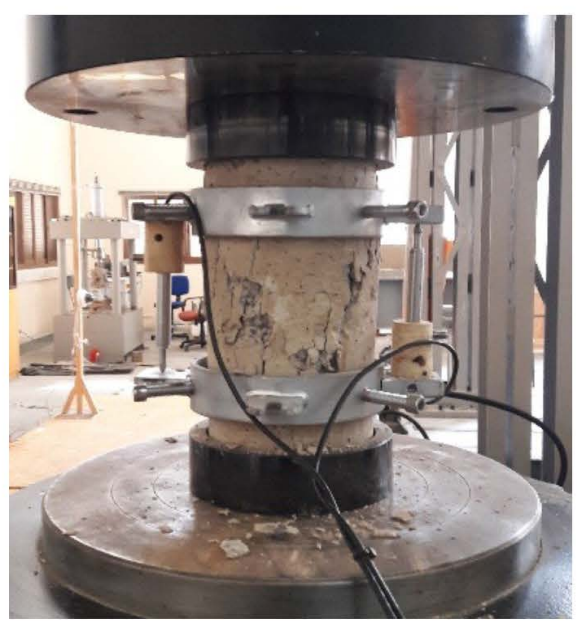

(f)

Fig. 6. (a)-(e): Stress-strain behavior of samples for all five sets, (f): stress-strain test setup 


\section{International Journal of Applied Science and Engineering}

Junaid et al., International Journal of Applied Science and Engineering, 18(5), 2020339
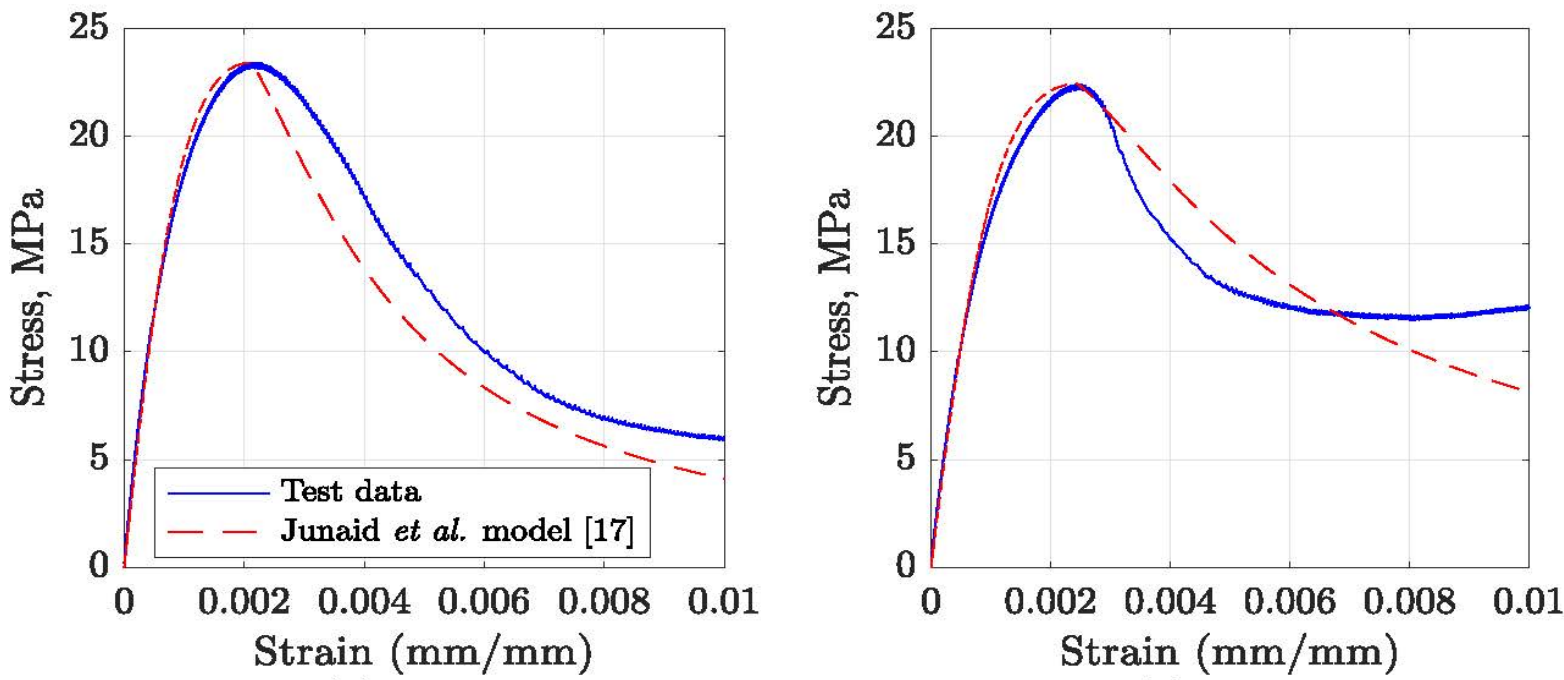

(a): S1M4

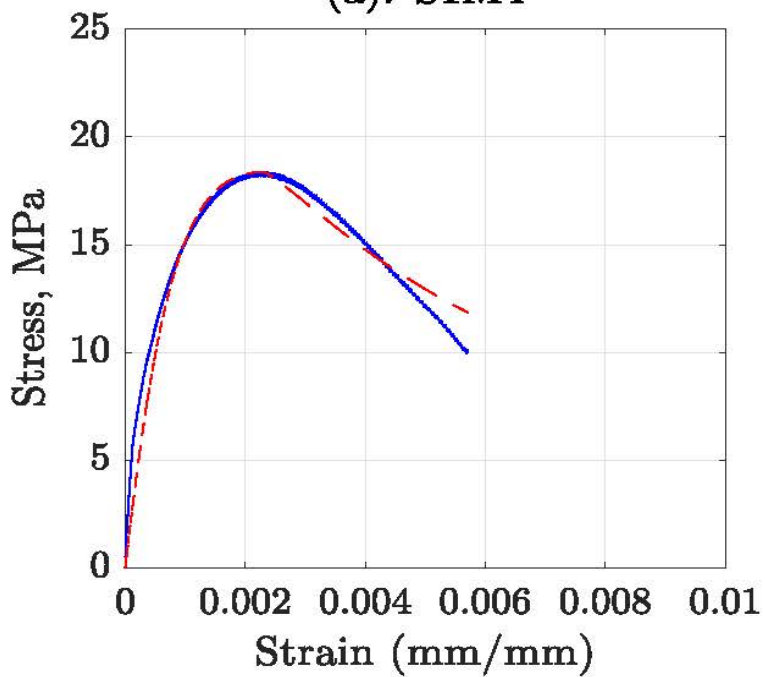

(b): S1M5

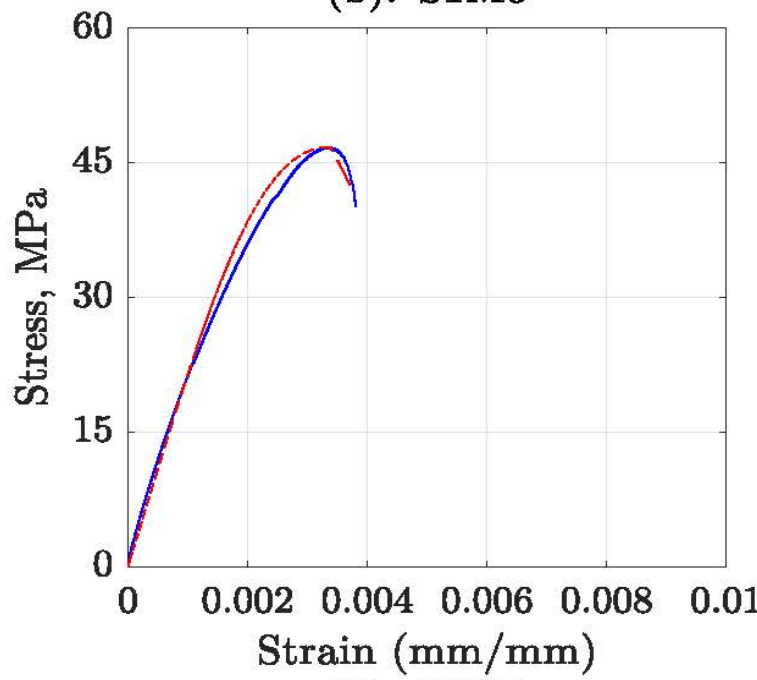

(c): S1M3

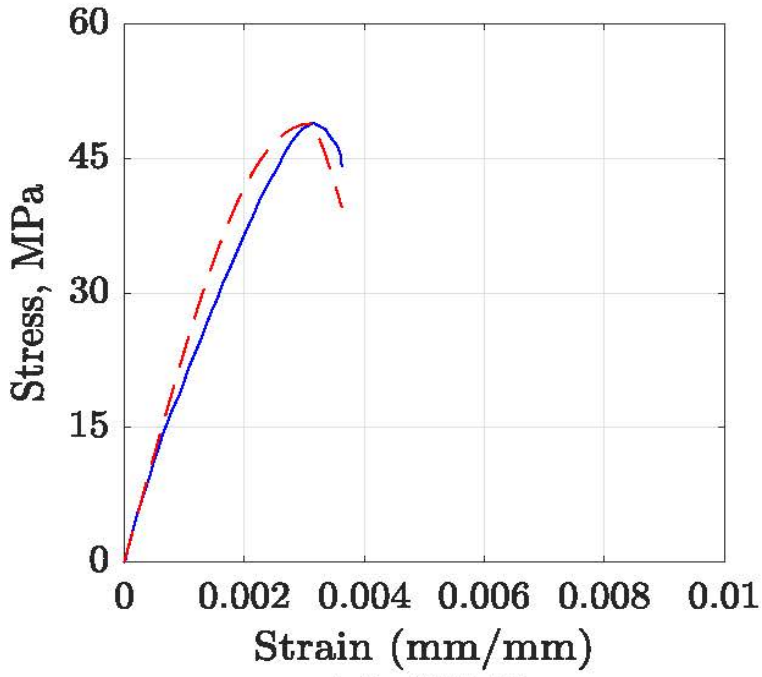

(d): S2M4

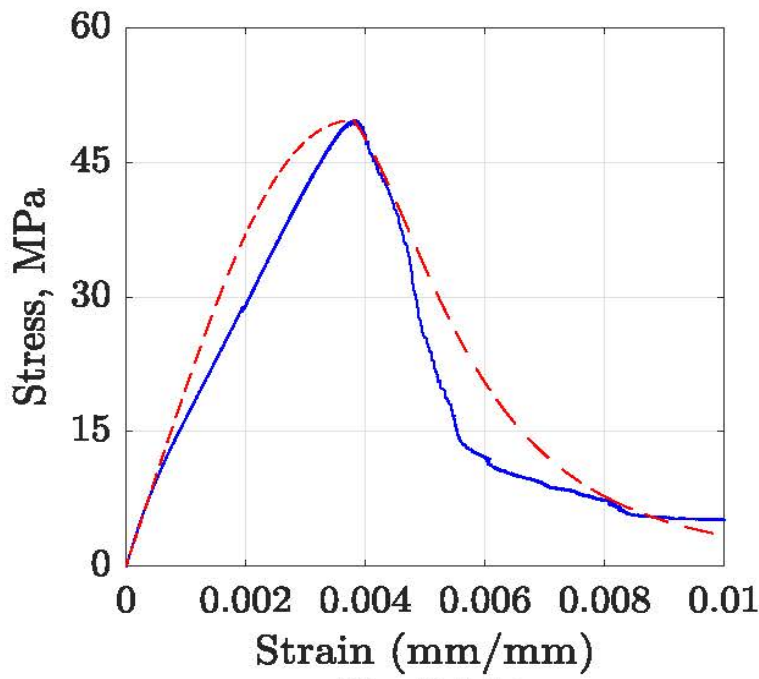

(e): S2M5

(f): S3M4

Fig. 7. (a)-(f): Comparison of experimental results of stress-strain behavior to the modified Junaid et al. (2017) model's prediction 


\section{International Journal of Applied Science and Engineering}

Junaid et al., International Journal of Applied Science and Engineering, 18(5), 2020339

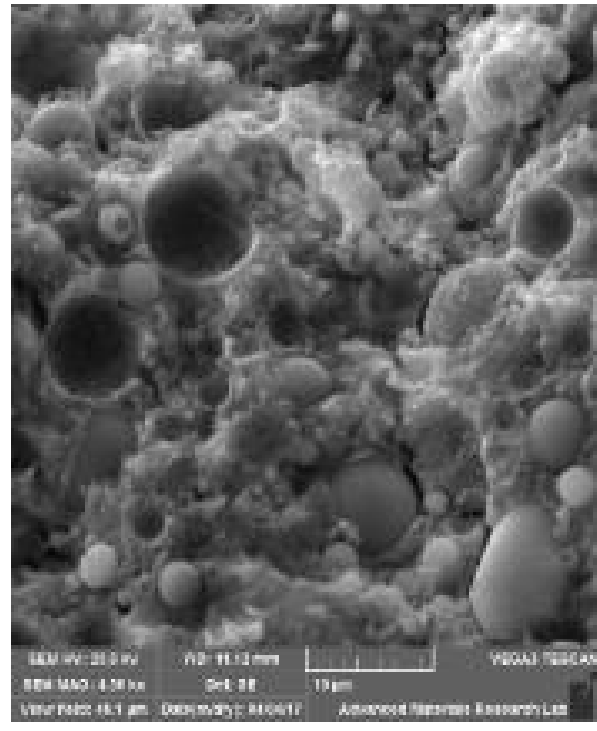

(a)

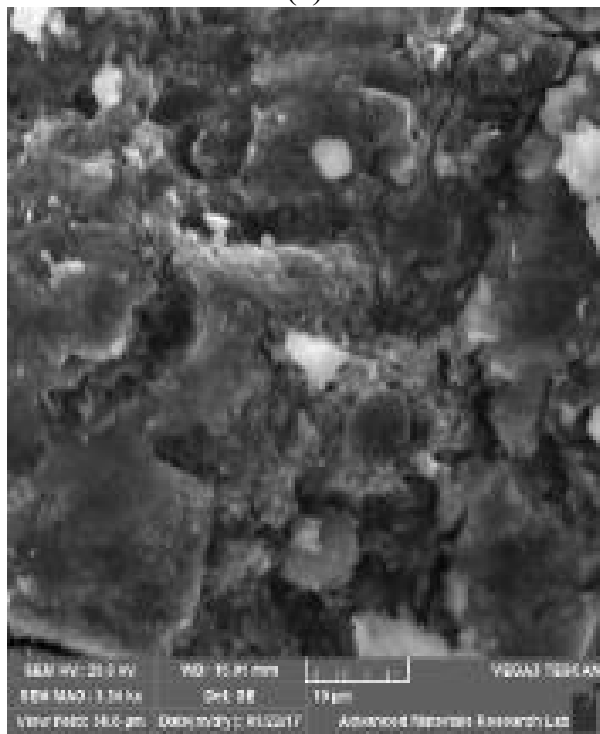

(c)

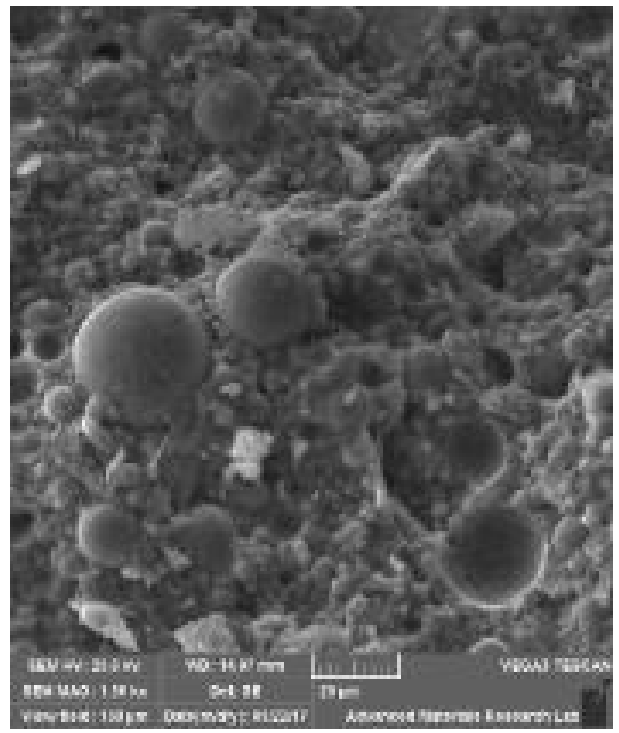

(b)

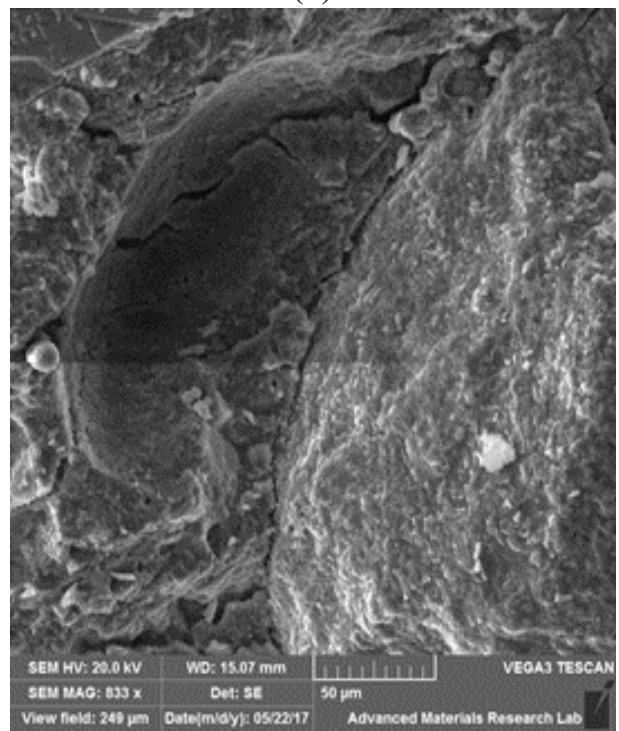

(d)

Fig. 8. SEM images for: (a) S1M1, (b) S1M2, (c) S1M4, (d) S1M5

\subsection{Scanning Electron Microscopy (SEM)}

Scanning electron microscopy (SEM) was conducted on all the mixes of this study in order to understand the morphology of the different specimens and analyse their reaction products. The correlation between the microstructure of the different mixes and their mechanical behaviour can also be understood using this test. In Set 1 (which was activated using only sodium hydroxide) the reaction gel detected was less than the rest of the mixes which contain the additional sodium silicate solution. This was more pronounced when only fly ash was used as a reactive solid. It was also noticed that the increase in GGBFS content in the AAB mix not only increases the amount of reaction gel, but also produces more compact and homogeneous specimens. In the case of S1M1 and S1M2 the SEM graphs show a heterogeneous structure with unreacted fly ash particles, and other regions of discontinuity in the geopolymer paste as seen in Fig. 8 (a) and (b).

The presence of unreacted fly ash particles indicates that the degree of reaction is low to moderate. On the other hand, Fig. 8 (c) and (d), for the mixes containing $80 \%$ and $100 \%$ GGBFS respectively, show more homogeneous, compact, and uniform microstructure, with no detection of individual unreacted or partially reacted particles. Fly ash particles usually need more time to be fully react compared to GGBFS particles due to larger surface area (Soutsos et al., 2016).

Fig. 9(a) and (b) shows that when a higher amount of GGBFS was added in the AAB mix, the reaction gel was found to be more homogeneously distributed in the paste, rather than acting as a shell surrounding the particle as in 


\section{International Journal of Applied Science and Engineering}

Junaid et al., International Journal of Applied Science and Engineering, 18(5), 2020339

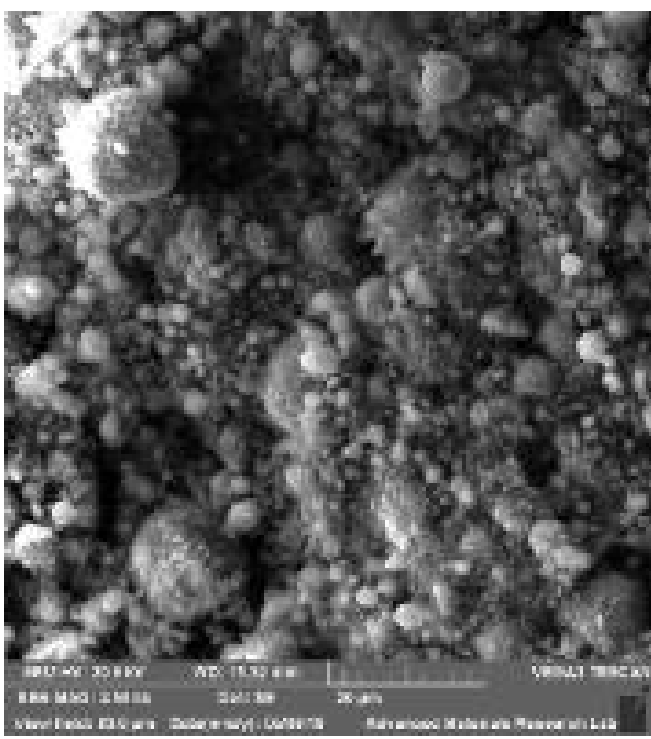

(a)

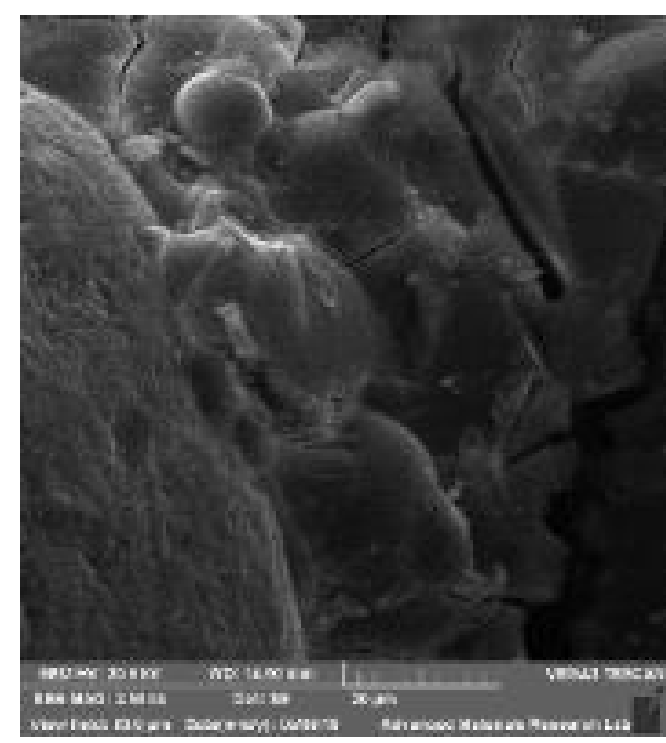

(b)

Fig. 9. SEM images for: (a) S3M1, (b) S3M5

the case where fly ash was the dominant binder. Fig. 9(a) shows fly ash particles with very thin layer of the geopolymer reaction gel. This thin layer may inhibit the production of a further reaction gel (Xie and Kayali, 2014) due to preventing more alumina and silica to dissolute from the surface of the fly ash particle.

As shown in Fig. 10 (a) the micrograph of Mix S5M4 shows a very compact specimen with no detectable microcracks, no unreacted particles, and with reaction gel present everywhere in the sample. More gel formation in the AABs matrix results in a higher compressive strength (Xie and Kayali, 2014). This was the reason for the high compressive

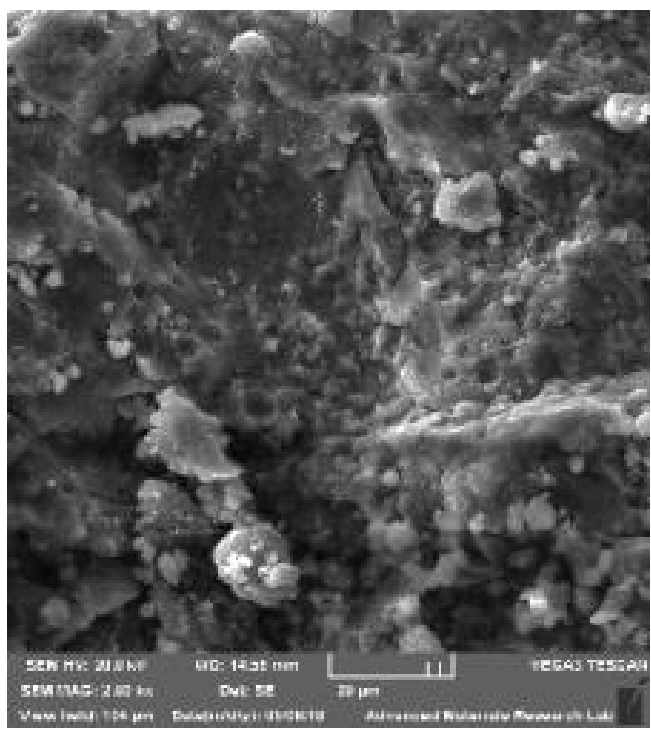

(a) strength for mix S5M4. Furthermore, the micrograph for mix S2M1 that recorded very low compressive strength, had a porous microstructure with large voids as shown in Fig. 10 (b).

It is also worth mentioning that the micrograph of the specimens of the different sets in this study indicated that an increase in the ratio of sodium silicate to sodium hydroxide $(\mathrm{SS} / \mathrm{SH})$ resulted in a smoother and denser paste with less pores and less fractured surfaces. Fig. 11(a) to Fig. 11(e) show how the increase of silicate solution decreased the number of unreacted fly ash particles and reduced the number of micro-cracks while GGBFS is absent.

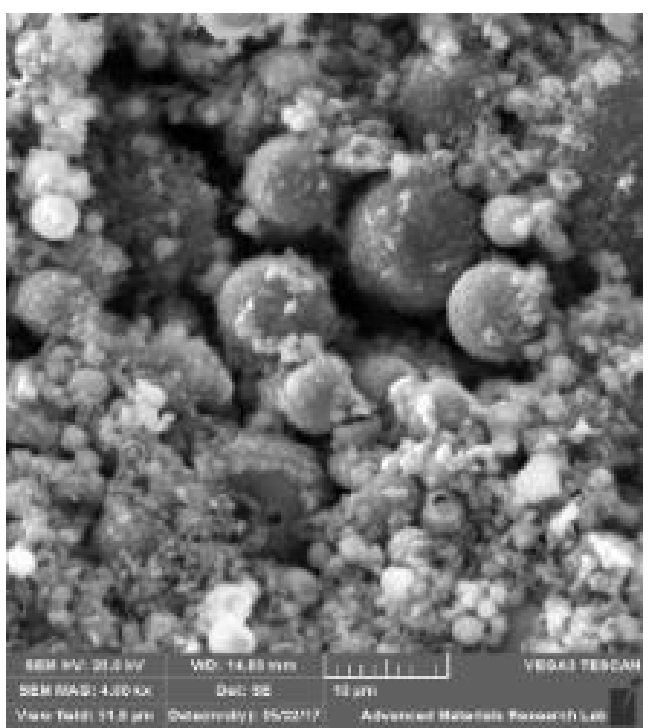

(b)

Fig. 10. SEM images (a) S5M4, (b) S2M1 


\section{International Journal of Applied Science and Engineering}

Junaid et al., International Journal of Applied Science and Engineering, 18(5), 2020339

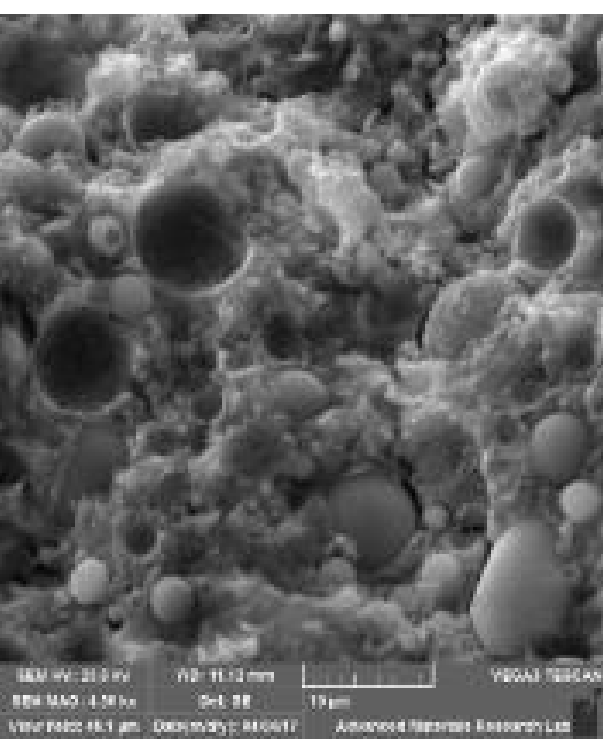

(a)

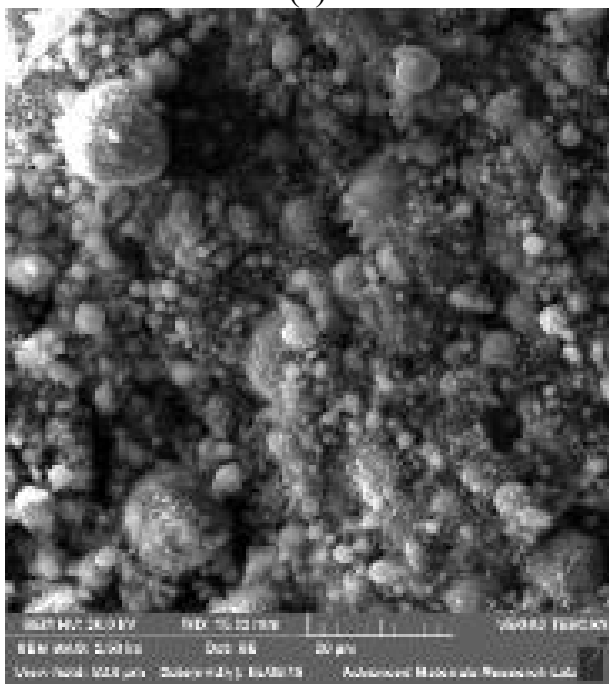

(c)

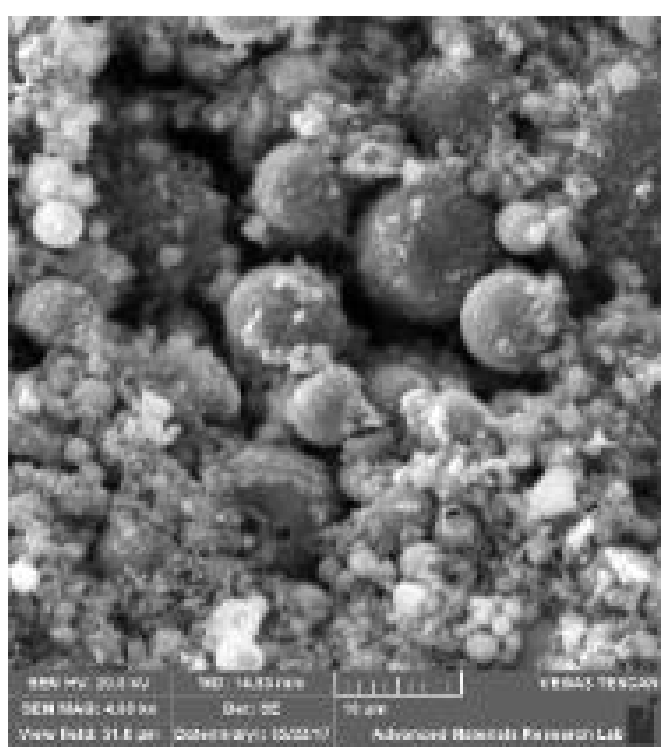

(b)

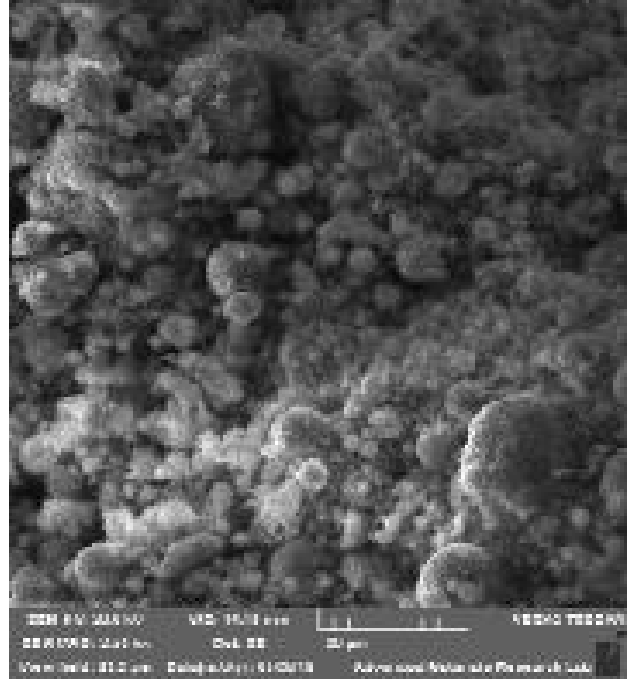

(d)

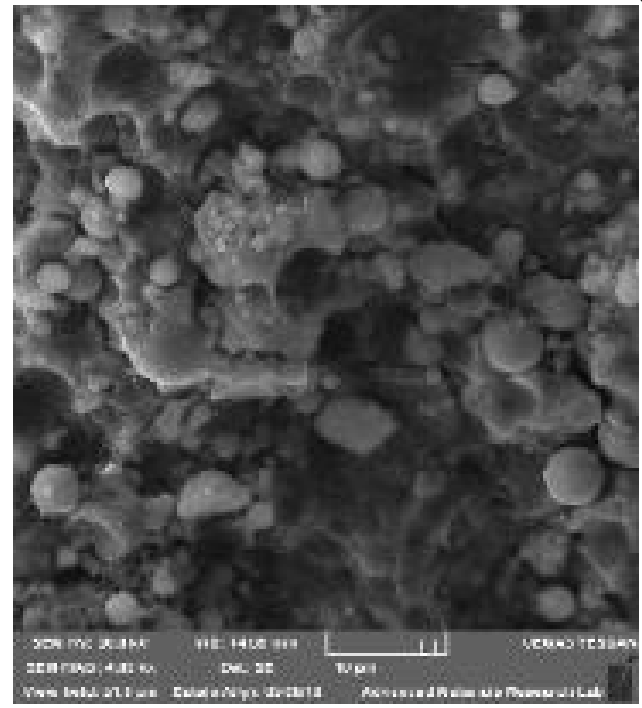

(e)

Fig. 11. Comparison of SEM images: (a) S1M1, (b) S2M1, (c) S3M1, (d) S4M1, (e) S5M1 


\section{International Journal of Applied Science and Engineering}

Junaid et al., International Journal of Applied Science and Engineering, 18(5), 2020339
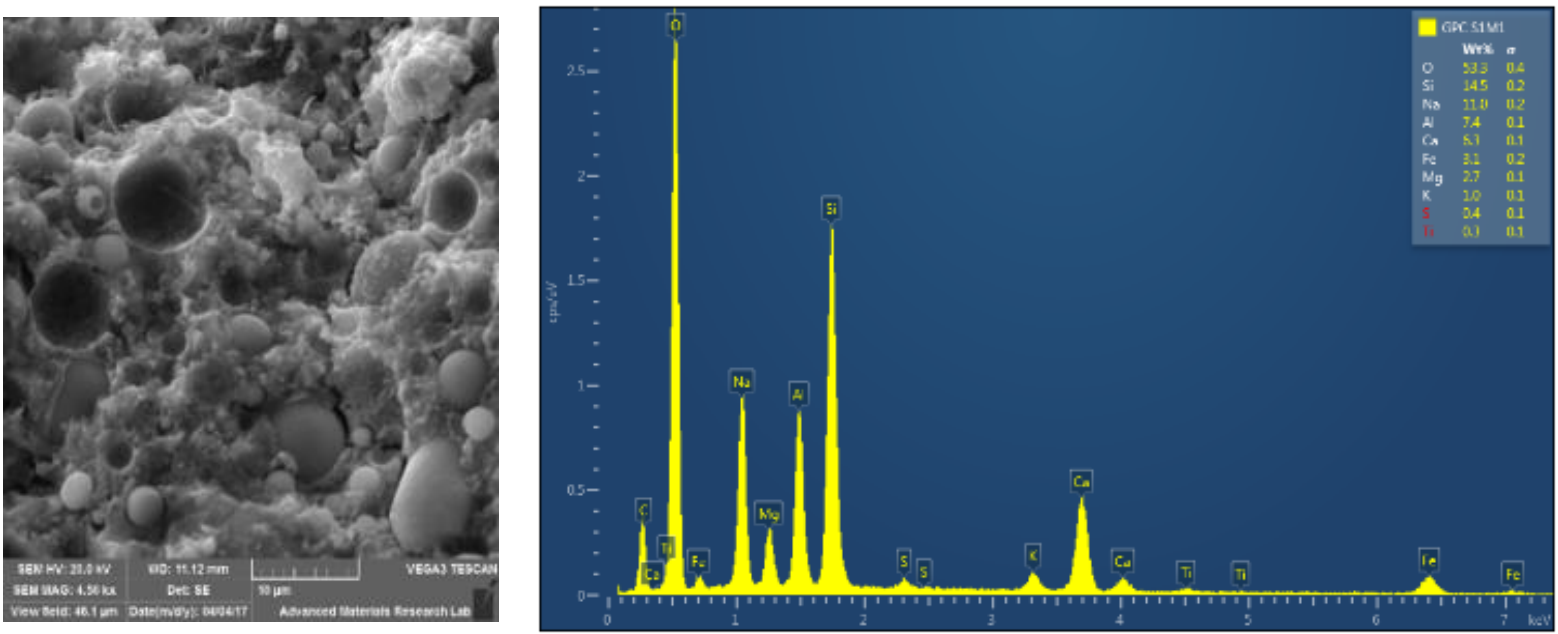

Fig. 12. EDS result of mix S1M1

\subsection{Energy Dispersive X-ray Spectroscopy (EDS)}

Energy Dispersive X-ray Spectroscopy (EDS) was also conducted to further investigate the effect of composition on the mechanical properties of such concretes. In fly ash based AABs, N-A-S-H and C-A-S-H are considered the main reaction products of the geopolymerisation. Whereas when GGBFS is added to the mix, C-S-H gel becomes the main reaction product (Nath and Sarker, 2014; Xie and Kayali, 2014). The Si to $\mathrm{Al}$ ratio for the reaction product measured from the quantitative EDS of mix S1M1 (Fig. 12) was found to be 2.0, which falls within the range (1.8-2.0) of reported values for the alumino-silicate gel resulting from activating fly ash by only $\mathrm{SH}$ as the alkali activator (Junaid et al., 2014b). Meanwhile, $\mathrm{Na} / \mathrm{Al}$ ratio of 1.5 indicated higher amount of reaction product, mainly N-A-S-H gel. Unreacted fly ash particles had lower amounts of $\mathrm{Na}$, and high amounts of $\mathrm{Si}, \mathrm{Al}$, and $\mathrm{O}$ as predicted. Moreover, some traces of calcium carbonates $\left(\mathrm{CaCO}_{3}\right)$ were detected in some areas, mainly the areas with white-colour material in the SEM micrograph of Fig. 12. This can be further corroborated by studying the EDS images where $\mathrm{Ca}, \mathrm{O}$, and $\mathrm{C}$ overlap.

Lower Al amount was found in S1M2 mix sample due to the inclusion of GGBFS which contains lower amounts of alumina than fly ash, and higher $\mathrm{Ca} / \mathrm{Si}$ ratio (0.72) indicated the presence of C-S-H gel in this mix. In mix S1M3, a relatively large amount of $\mathrm{Zn}, \mathrm{Fe}, \mathrm{K}$, and $\mathrm{Mg}$ besides $\mathrm{Si}$, $\mathrm{Na}$, $\mathrm{Al}$, and $\mathrm{Ca}$ were detected as shown in Fig. 13. According to Duxson et al. (2007), polymerization is influenced by impurities like haematite that fill the actual polymeric binders and as a result affect the strength development of the concrete matrix to a great extent. C-A-S-H was found to be the main reaction gel in this mix due to high ratios of $\mathrm{Si} / \mathrm{Al}$ and $\mathrm{Ca} / \mathrm{Si}$, along with rich amounts of N-A-S-H and $\mathrm{C}-\mathrm{S}-\mathrm{H}$ gels due to high ratios of $\mathrm{Na} / \mathrm{Al}$ and $\mathrm{Ca} / \mathrm{Si}$, respectively. The coexistence of N-A-S-H and C-A-S-H was also reported in literature (Deb et al., 2014). The presence of white crystals with high $\mathrm{Fe}$ content, most probably ferrous or ferric oxides, was noticed in the mixes with 80 and 100 percent FA.

The mixes of set 2 and 3 generally had high amounts of all three reaction gels, with C-S-H gel being the dominant. Very high accumulation of calcium carbonate in some areas with some $\mathrm{Ca}, \mathrm{C}$, and $\mathrm{O}$ was also reported in these two sets, especially with higher replacement of fly ash by GGBFS. In addition to that, noticeable quantities of impurities such as $\mathrm{K}, \mathrm{Ti}, \mathrm{S}$, and Fe existed almost in all areas of the samples of sets 2 and 3 .

Sets 4 and 5 (having sodium silicate to sodium hydroxide ratios of 2.5 and 2.0, respectively) experienced little to moderate quantities of reaction products (dominant was CA-S-H) that were poorly distributed in the concrete samples, and in some cases only one type of reaction gel was detected. It is shown in Fig. 14 and Fig. 15 that the samples in this set were filled with many unreacted particles of highly concentrated amounts of $\mathrm{Si}, \mathrm{Al}$, and $\mathrm{O}$. This supports the findings of lower compressive strength recorded by the samples of this set as mentioned earlier in this paper. This could be attributed to the lower $\mathrm{Na}_{2} \mathrm{O} / \mathrm{SiO}_{2}$ molar ratio in the AABs mix when varying the sodium silicate to sodium hydroxide ratio in the alkali solution from 1.5 to 2.5 which leads to slight drop in the overall strength as also reported by Nath and Sarker (2015). 


\section{International Journal of Applied Science and Engineering}

Junaid et al., International Journal of Applied Science and Engineering, 18(5), 2020339
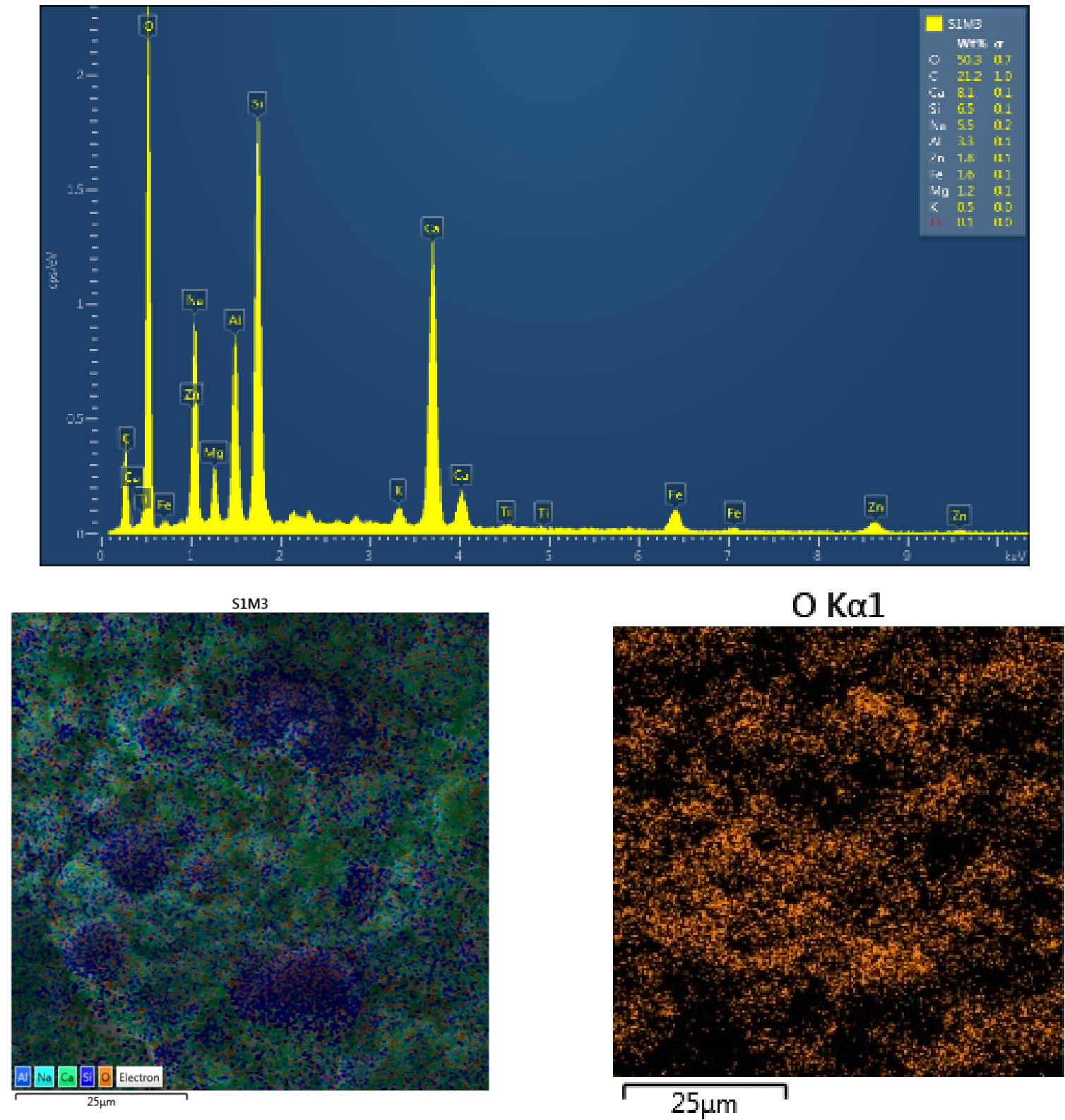

$\mathrm{C}$ K $\alpha 1 \_2$

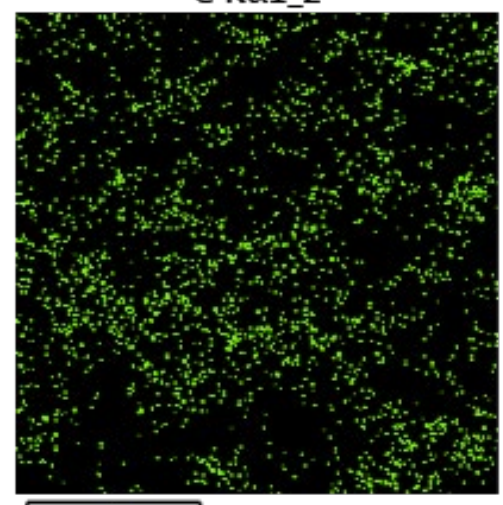

$25 \mu \mathrm{m}$
$\mathrm{Ca} \mathrm{K} \alpha \mathbf{1}$

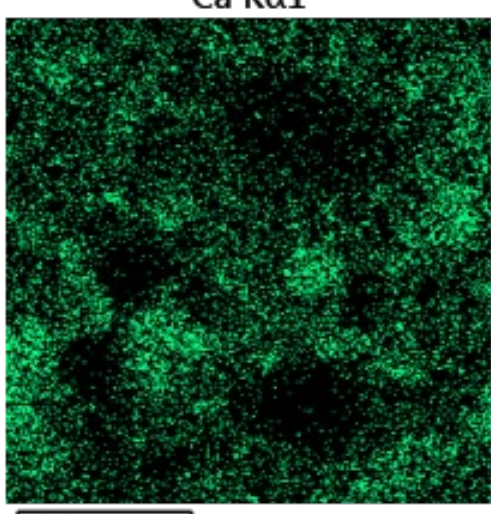

$25 \mu \mathrm{m}$
Si $K \alpha 1$

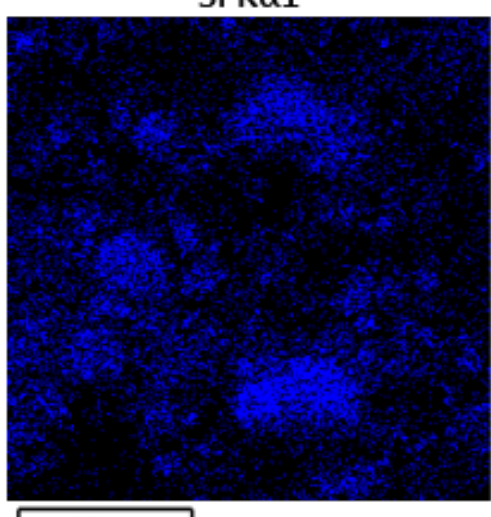

$25 \mu \mathrm{m}$ 


\section{International Journal of Applied Science and Engineering}

Junaid et al., International Journal of Applied Science and Engineering, 18(5), 2020339

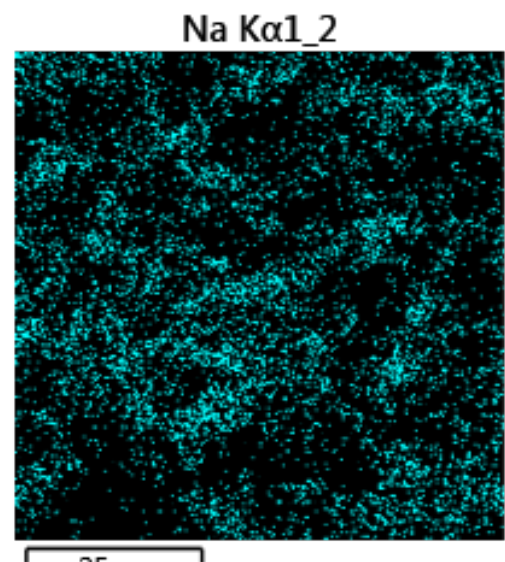

$25 \mu \mathrm{m}$

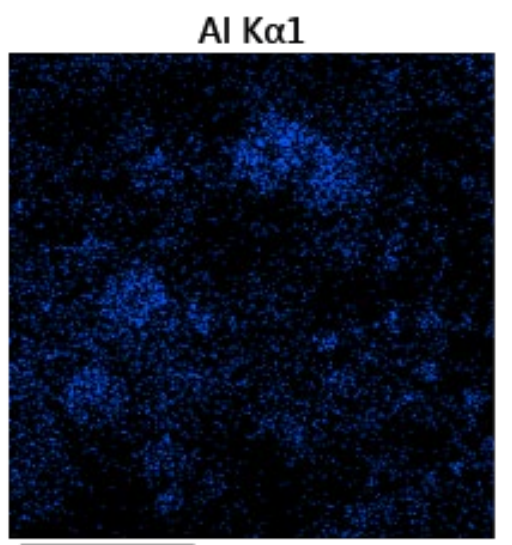

$\longdiv { 2 5 \mu \mathrm { m } }$
Fe K $\alpha 1$

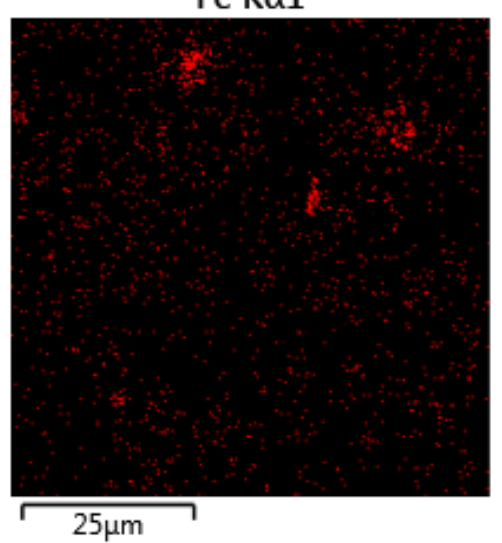

Fig. 13. Detailed EDS result of mix S1M3 showing major individual element occurrence
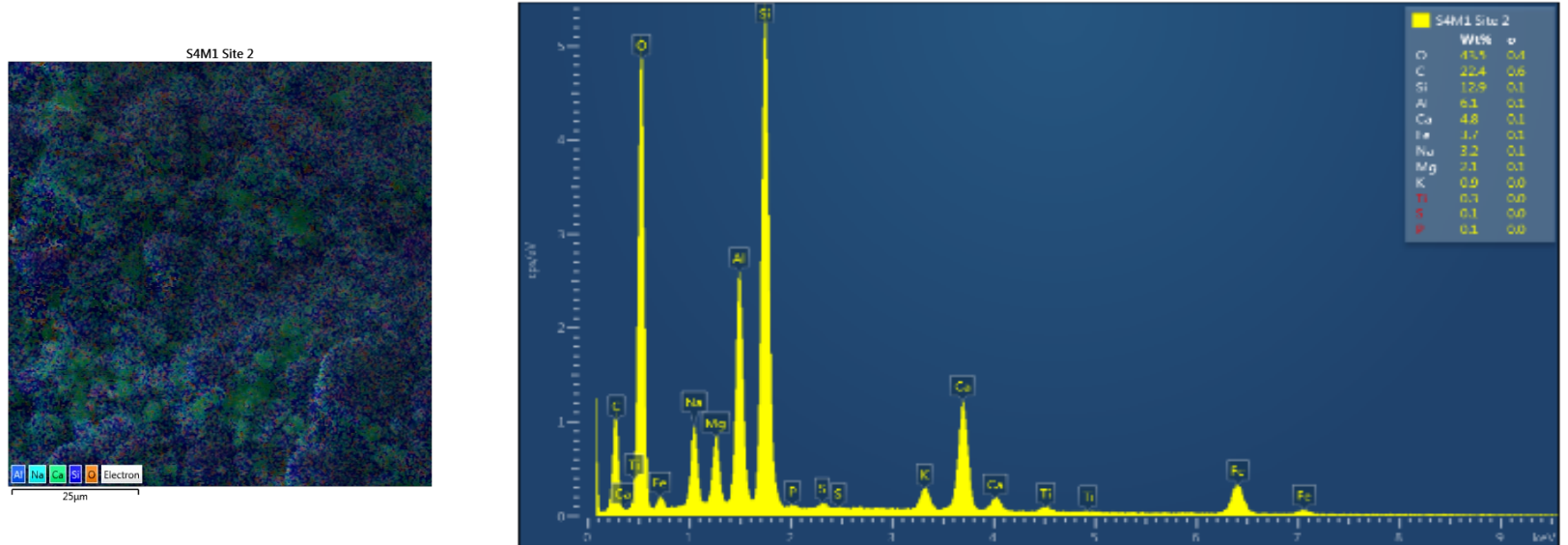

Fig. 14. EDS result of mix S4M1

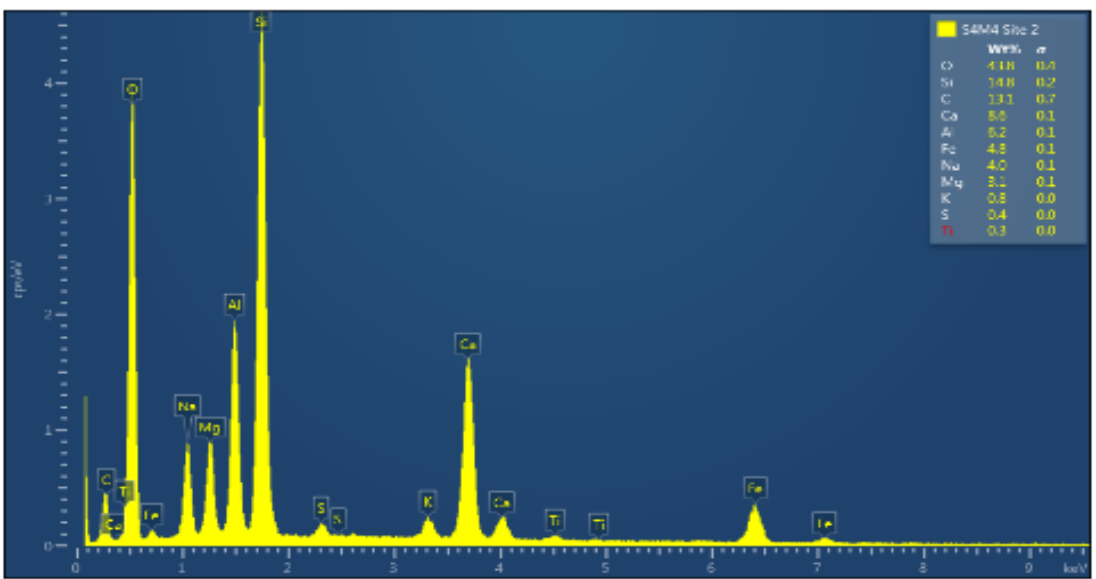

Fig. 15. EDS result of mix S4M4

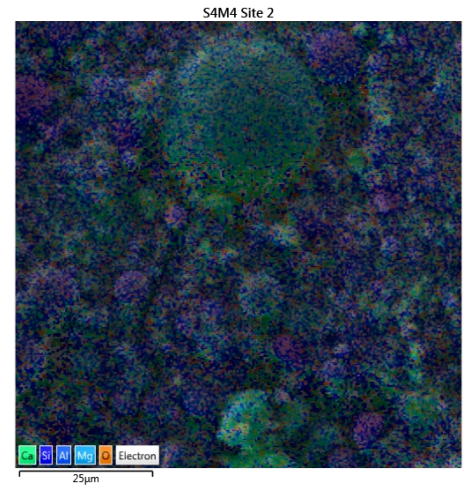




\section{SUMMARY AND CONCLUSIONS}

This paper presents results from an experimental study conducted to determine the mechanical and morphological properties of ambient cured alkaline activated binder (AABs). The testing program determines the dependency of AABs' strength characteristics on various parameters such as proportion and type of precursor, ratio and type of activators used, and curing time. The strength properties reported are the compressive strength, splitting tensile strength, flexural strength and modulus of elasticity. Moreover, the compressive stress-strain response of AABs is also determined. Based on the findings of this study the following conclusions can be drawn:

- Adding sodium silicate (SS) solution to the AAB concrete can increase the strength of the binder however it results in low modulus of elasticity of the produced concrete.

- The gain in compressive strength from 7 days to 28 days is relatively slow in the samples activated by both sodium hydroxide ( $\mathrm{SH}$ ) and sodium silicate (SS), when compared to the samples of the mixes activated by $\mathrm{SH}$ only.

- The compressive strength and splitting tensile strength of $\mathrm{AAB}$ concrete follow a similar trend in strength development. Similar to OPC, the splitting tensile strength values were approximately $7-10 \%$ of their corresponding compressive strength. Moreover, there was no change in splitting tensile strength after the first 7 days.

- Flexural strength is also a fraction of the compressive strength value and follows a trend similar to its compressive strength. Moreover, increasing the amount of SS in the mix has a positive impact on the flexural strength up until a certain ratio of SS to SH.

- The elastic modulus of AAB concrete is usually lower than OPC of comparable strength. However, the addition of GGBFS increases the elastic modulus, in contrast with the addition of $\mathrm{SS}$, which reduces the elastic modulus of the AAB concrete samples. The density of AAB concrete is comparable to that of OPC concrete.

- Stress-strain curves behaviour of the samples in this study indicates that for the ratio of SS to SH up to 2, a higher percentage replacement of fly ash by GGBFS gives a higher compressive strength but a lower peak strain. In addition, increased GGBFS and SS amounts added to the AABs concrete system gives a more brittle failure. The stress strain behaviour of AABs can be predicted by established analytical models as shown in the results.

- SEM analysis results supports the strength tests results by showing positive effect of increasing the amount of GGBFS added to the mix with the increase of (SS/SH) ratio, up to a ratio of 2 . Beyond this, more unreacted particles and micro-cracks in the paste were detected leading to decrease in strength.

- EDS images show high accumulations of all three types of reaction gels (C-H-S, N-A-S-H and C-A-S-H) in the mixes that recorded high strengths, along with noticeable quantities of chemical impurities that improves the strength of the AAB concrete samples.

\section{ACKNOWLEDGEMENTS}

The authors would like to appreciate the support of the Sustainable Construction Materials and Structural Systems (SCMASS) research group at the University of Sharjah. The help in the experimental stage of this project, provided by Eng. Abdulrahman Mustafa and Eng. Ahmad Shweiki from the University of Sharjah, is also appreciated. This research project was funded by the University of Sharjah (research grant number 1602040128-P).

\section{REFERENCES}

Ahmed, F.B., Biswas, R.K., Ahsan, K.A., Islam, S., Rahman, M.R. 2021. Estimation of strength properties of geopolymer concrete, Materials Today: Proceedings. Elsevier Ltd, (xxxx). doi: 10.1016/j.matpr.2021.03.002.

ASTM C39/C39M - 16b, 2016. Standard test method for compressive strength of cylindrical concrete specimens, ASTM International, 1-7. doi: 10.1520/C0039.

ASTM C496, 2006. Standard test method for splitting tensile strength of cylindrical concrete specimens, ASTM International, 1-5. doi: 10.1520/C0496.

Binici, H. 2013. Engineering properties of geopolymer incorporating slag, fly ash, silica sand and pumice, Advances in Civil and Environmental Engineering, 01, 108-123.

Chandrakanth, V., Koniki, S. 2020. Effect of elevated temperature on geo-polymer concrete - A Review, E3S Web of Conferences, 184, 1-4. doi: 10.1051/e3sconf/202018401090.

Chindaprasirt, P., De Silva, P., Sagoe-Crentsil, K., Hanjitsuwan, S. 2012. Effect of $\mathrm{SiO} 2$ and $\mathrm{Al} 2 \mathrm{O} 3$ on the setting and hardening of high calcium fly ash-based geopolymer systems, Journal of Materials Science, 47, 4876-4883. doi: 10.1007/s10853-012-6353-y.

Collins, M.P., Mitchell, D., MacGregor, J.G. 1993. Structural design considerations for high-strength concrete, Concrete International, 15, 27-34.

Davidovits, J. 1991. Geopolymers - Inorganic polymeric new materials, Journal of Thermal Analysis, 37, 16331656. doi: 10.1007/BF01912193.

Davidovits, J. 1994. Global warming impact on the cement and aggregate industries, 6, 263-278.

Davidovits, J., Orlinski, J. (Eds.) 1988. Soft mineralurgy and geopolymers, Proceedings of the 1st International Conference on Geopolymer '88, 1, 25-48. 
Deb, P.S., Nath, P., Sarker, P.K. 2014. The effects of ground granulated blast-furnace slag blending with fly ash and activator content on the workability and strength properties of geopolymer concrete cured at ambient temperature, Materials and Design. Elsevier Ltd, 62, 3239. doi: 10.1016/j.matdes.2014.05.001.

Diaz, E.I., Allouche, E.N., Eklund, S. 2010. Factors affecting the suitability of fly ash as source material for geopolymers', Fuel. Elsevier Ltd, 89, 992-996. doi: 10.1016/j.fuel.2009.09.012.

Diaz-Loya, E.I., Allouche, E.N., Vaidya, S. 2011. Mechanical properties of fly-ash-based geopolymer concrete, ACI Materials JournalMaterials Journal, 108, 300-306.

Duxson, P., Fernández-Jiménez, A., Provis, J.L., Lukey, G.C., Palomo A., van Deventer, J.S.J. 2007. Geopolymer technology: The current state of the art, Journal of Materials Science, 42, 2917-2933. doi: 10.1007/s10853006-0637-z.

Fernández-jiménez, A. 2006. Engineering properties of alkali-activated fly ash concrete, ACI Materials Journal, 103. doi: $10.14359 / 15261$

Ganesh, A.C., Muthukannan, M. 2018. A review of recent developments in geopolymer concrete, International Journal of Engineering \& Technology, 7, 696. doi: 10.14419/ijet.v7i4.5.25061.

Hardjito, D., Cheak, C.C., Ing, C.H.L. 2008. Strength and setting times of low calcium fly ash-based geopolymer mortar, Modern Applied Science, 2, 3-11. doi: 10.5539/mas.v2n4p3.

Hassan, A., Arif, M., Shariq, M. 2019. Use of geopolymer concrete for a cleaner and sustainable environment - A review of mechanical properties and microstructure, Journal of Cleaner Production. Elsevier B.V., 223, 704728. doi: 10.1016/j.jclepro.2019.03.051.

Junaid, M.T., Kayali, O., Khennane, A., Black, J. 2015. A mix design procedure for low calcium alkali activated fly ash-based concretes, Construction and Building Materials. Elsevier Ltd, 79, 301-310. doi: 10.1016/j.conbuildmat.2015.01.048.

Junaid, M.T., Khennane, A., Kayali, O. 2015. Performance of fly ash based geopolymer concrete made using nonpelletized fly ash aggregates after exposure to high temperatures, Materials and Structures/Materiaux et Constructions, 48, 3357-3365. doi: 10.1617/s11527-0140404-6.

Junaid, M.T., Khennane, A., Kayali, O. 2016. Stress-strain behaviour of alkali activated fly-ash concrete at elevated temperatures, 2nd International Conference on Advances in Cement and Concrete Technology in Africa.

Junaid, M.T., Khennane, A., Kayali, O., Sadaoui, A., Picard, D., Fafard, M. 2014a. Aspects of the deformational behaviour of alkali activated fly ash concrete at elevated temperatures, Cement and Concrete Research. Elsevier Ltd, 60, 24-29. doi: 10.1016/j.cemconres.2014.01.026.

Junaid, M.T., Khennane, A., Kayali, O., Sadaoui, A., Picard, D., Fafard, M. 2014b. Aspects of the deformational behaviour of alkali activated fly ash concrete at elevated temperatures, Cement and Concrete Research. Elsevier Ltd, 60, 24-29. doi: 10.1016/j.cemconres.2014.01.026.

Junaid, T.M., Kayali, O., Khennane, A. 2017. Response of alkali activated low calcium fly-ash based geopolymer concrete under compressive load at elevated temperatures, Materials and Structures/Materiaux et Constructions. Springer Netherlands, 50, 1-10. doi: 10.1617/s11527016-0877-6.

Kong, D., Sanjayan, J., Sagoe-Crentsil, K. 2006. The behaviour of geopolymer paste and concrete at elevated temperatures, in International Conference on Pozzolan, Concrete and Geopolymer, Khon Kaen, Thailand, 105118.

Lee, N.K., Lee, H.K. 2013. Setting and mechanical properties of alkali-activated fly ash/slag concrete manufactured at room temperature, Construction and Building Materials. Elsevier Ltd, 47, 1201-1209. doi: 10.1016/j.conbuildmat.2013.05.107.

Li, Y., Shen, L., Mirmoghtadaei, R., Ai, L. 2017. A Design of Experiment Approach to Study the Effects of Raw Material on the Performance of Geopolymer Concrete, Advances in Civil Engineering Materials, 6, 526-549. https://doi.org/10.1520/ACEM20160007.

Lloyd, N.A., Rangan, B.V. 2010. Geopolymer concrete with fly ash, Sustainable Construction Materials and Technologies, 7, 1-12. doi: 10.1063/1.4775784.

Malhotra, V.M. 2002. Introduction: Sustainable development and concrete technology, Concrete International, 24, 22.

McCaffrey, R. 2002. Climate change and the cement industry, GCL Magazine, 5. doi: 10.1001/jama.275.18.1405.

Mindess, S., Young, J.F., Darwin, D. 2003. Concrete. Pearson Education Inc.

Nath, P., Sarker, P.K. 2014. Effect of GGBFS on setting, workability and early strength properties of fly ash geopolymer concrete cured in ambient condition, Construction and Building Materials. Elsevier Ltd, 66, 163-171. doi: 10.1016/j.conbuildmat.2014.05.080.

Nath, P., Sarker, P.K. 2015. Use of OPC to improve setting and early strength properties of low calcium fly ash geopolymer concrete cured at room temperature, Cement and Concrete Composites. Elsevier Ltd, 55, 205-214. doi: 10.1016/j.cemconcomp.2014.08.008.

Nath, P., Sarker, P.K. 2017. Flexural strength and elastic modulus of ambient-cured blended low-calcium fly ash geopolymer concrete, Construction and Building Materials. Elsevier Ltd, 130, 22-31. doi: 10.1016/j.conbuildmat.2016.11.034.

Neville, A.M., Brooks, J.J. 2010. Concrete technology. Second, Pearson Education Limited. Second. England: Pearson.

Ravikumar, D., Peethamparan, S., Neithalath, N. 2010. Structure and strength of $\mathrm{NaOH}$ activated concretes containing fly ash or GGBFS as the sole binder, Cement 


\section{International Journal of Applied Science and Engineering}

Junaid et al., International Journal of Applied Science and Engineering, 18(5), 2020339

and Concrete Composites. Elsevier Ltd, 32, 399-410. doi: 10.1016/j.cemconcomp.2010.03.007.

Shehab, H.K., Eisa, A.S., Wahba, A.M. 2016. Mechanical properties of fly ash based geopolymer concrete with full and partial cement replacement, Construction and Building Materials. Elsevier Ltd, 126, 560-565. doi: 10.1016/j.conbuildmat.2016.09.059.

Shrivas, R., Paramkusam, B.R., Dwivedi, S.B. 2021. Effect of alkali concentration on strength development in jointly activated pond ash-GGBFS mixtures through geopolymeric reactions, KSCE Journal of Civil Engineering. doi: 10.1007/s12205-021-1869-9.

Soutsos, M., Boyle, A.P., Vinai, R., Hadjierakleous, A., Barnett, S.J. 2016. Factors influencing the compressive strength of fly ash based geopolymers, Construction and Building Materials. Elsevier Ltd, 110, 355-368. doi: 10.1016/j. conbuildmat.2015.11.045.

ASTM C78 / C78M-21, Standard test method for flexural strength of concrete (Using Simple Beam with ThirdPoint Loading), ASTM International, West Conshohocken, PA, 2021, www.astm.org.

ASTM C469 / C469M-14e1, Standard test method for static modulus of elasticity and Poisson's ratio of concrete in compression, ASTM International, West Conshohocken, PA, 2014, www.astm.org

Topark-Ngarm, P., Chindaprasirt, P., Sata, V. 2015. Setting time, strength, and bond of high-calcium fly ash geopolymer concrete, Journal of Materials in Civil Engineering, 27, 04014198. doi: 10.1061/(ASCE) MT.1943-5533.0001157.

US Geological-Survey, 2013. Mineral commodity summaries 2013. doi: 10.3133/mineral2013.

Van Jaarsveld, J.G.S., Van Deventer, J.S.J., Lukey, G.C. 2002. The effect of composition and temperature on the properties of fly ash-and kaolinite-based Geopolymers, Chemical Engineering Journal, 89, 63-73.

Wattimena, O.K., Antoni, Hardjito, D. 2017. A review on the effect of fly ash characteristics and their variations on the synthesis of fly ash based geopolymer, AIP Conference Proceedings, 1887. doi: 10.1063/1.5003524.

Xie, J., Kayali, O. 2014. Effect of initial water content and curing moisture conditions on the development of fly ashbased geopolymers in heat and ambient temperature, Construction and Building Materials. Elsevier Ltd, 67, 20-28. doi: 10.1016/j.conbuildmat.2013.10.047.

Yadollahi, M.M., Benli, A. 2017. Stress-strain behavior of geopolymer under uniaxial compression, Computers and Concrete, 20, 381-389. doi: 10.12989/cac.2017.20.4.381 